\title{
La represión penal del acoso en el trabajo
}

\section{Criminal punishment of harassment at work}

\author{
Juan Antonio Altés Tárrega \\ Profesor Titular de Derecho del Trabajo y de la Seguridad Social \\ Universitat de València. Estudi General \\ ORCID ID: 0000-0003-1530-8545
}

Recibido: 5/11/2020

Aceptado: 28/12/2021

doi: https://doi.org/10.20318/labos.2021.6046

Resumen: $\quad$ En este artículo se estudian los delitos de acoso laboral y acoso sexual en el trabajo. Se analizan los elementos de los tipos delictivos y se intenta, cuando es posible, aportar una visión laboral que posibilite una mejor aplicación práctica de la represión penal de estas conductas violentas.

Palabras clave: acoso laboral, acoso sexual, responsabilidad penal.

Abstract: This paper examines mobbing and sexual harassment at work. It analyses elements of these criminal offences and attempts, when possible, to enable a labour view that provides a better practical application for prosecuting and punishing these violent behaviours

Keywords: $\quad$ mobbing, sexual harassment, penal responsibility

\section{Introducción}

El reciente Convenio 190 de la OIT sobre violencia y acoso, cuyo proceso de ratificación por España se inició en el primer trimestre del 2020 determina en su art. 1.1.a que "la expresión «violencia y acoso» en el mundo del trabajo designa un conjunto de comportamientos y prácticas inaceptables, o de amenazas de tales comportamientos y prácticas, ya sea que se manifiesten en una sola vez o de manera repetida, que tengan por objeto, que causen o sean susceptibles de causar, un daño físico, psicológico, sexual o económico". Como puede observase la violencia y el acoso se tratan como un único concepto. Con ello se ha pretendido dar cobertura a un abanico más amplio de situaciones reprochables y dotar al concepto de mayor flexibilidad, facilitando su adaptación a las regulaciones nacionales ${ }^{2}$

\footnotetext{
* Trabajo realizado en el marco del I+D de Generación del Conocimiento sobre Violencia, Trabajo y Género (VITRAGE), Ref. PGC2018-094912-B-I00, del Programa Estatal de Generación de Conocimiento y Fortalecimiento Científico y Tecnológico del Sistema de I+D+I del Ministerio de Ciencia, Innovación e Universidades.

${ }^{1}$ Sobre el mismo PONS CARMENA, M. (2020), Acoso y violencia en el trabajo a la luz del Convenio OIT no 190, Labos, (1)2, pp. 30-60; YAGÜE BLANCO, S. (2020), Convenio 190 de la OIT sobre violencia y acoso: delimitación de su ámbito de aplicación ante la posible ratificación por Espańa, Revista General de Derecho del Trabajo y de la Seguridad Social, (57), pp. 498-538.

${ }^{2}$ OIT (2019), Informe V (1). Acabar con la violencia y el acoso en el mundo del trabajo. Ginebra: Oficina Internacional del Trabajo, p. 4. Recuperado (30-09-19) de https://www.ilo.org/wcmsp5/groups/public/---ed_norm/---relconf/documents/meetingdocument/wcms_637134.pdf.
} 
Sin embargo, tradicionalmente estos dos conceptos se han tratado de forma separada. Efectivamente, aunque obviamente el término violencia habría que entenderlo como omnicomprensivo de cualquier comportamiento, en sentido estricto se ha referido las agresiones directas que se producen en el marco de las relaciones laborales (lesiones, amenazas, agresiones verbales, abusos ) y suele clasificarse en función de quien la realiza como violencia externa, en la que el agresor no tiene ningún tipo de conexión con la relación laboral; violencia de servicios, donde el agresor es un cliente o usuario de los servicios que presta la empresa; y la violencia relacional en la que víctima y agresor forman parte de la relación laboral. En cambio, en el acoso se pone en relación con la violencia psicológica, con la presión ambiental que se impone a un sujeto, mediante un reiterado comportamiento de hostigamiento y persecución, muchas veces velado, con el fin de minar su voluntad y crearle un entorno intimidatorio y humillante

Todas estas manifestaciones violentas deben ser evitadas y para ello se requiere, en primer lugar, actuar en las empresas de forma preventiva, mediante campańas de información y sensibilización y, especialmente, mediante su integración en los planes de prevención de riesgos laborales. En este sentido, el acoso en el trabajo viene unánimemente considerado como un riesgo psicosocial frente al que la empresa está obligada a actuar.

En segundo lugar, es necesaria una política de intervención que proporcione una adecuada respuesta a las víctimas de estas conductas. Esta tutela se lleva a cabo en la empresa, implementando protocolos de intervención para proteger a las víctimas y lograr su rehabilitación social y laboral, pero también se activa desde distintas instancias judiciales y administrativas a fin de resarcir a las víctimas y depurar la responsabilidad laboral, civil, administrativa y penal de los agresores y de la empresa en la que tiene lugar el comportamiento.

Pues bien, este trabajo se centra en la depuración de la responsabilidad penal que recae sobre los sujetos que comenten actos de acoso, en sus distintas manifestaciones. Por tanto, no se trata la posible responsabilidad penal por otros actos violentos, ni la posible responsabilidad penal de la empresa por el acoso cometido por alguno de sus trabajadores, cuestiones realmente importantes, pero que resulta imposible abarcar en un estudio de estas características.

\section{El Acoso laboral en el Código penal (art. 173)}

El acoso laboral, también denominado acoso moral o acoso psicológico o, en inglés, mobbing (o bulling, bossing o stalking en función del contexto), se refiere a los ataques sistemáticos contra la dignidad de la persona, a la tortura psicológica y al hostigamiento moral que sufren los trabajadores en su entorno de trabajo, por actos cometidos por el empresario o por sus propios compañeros de trabajo $^{3}$, siendo ese carácter sistemático, que se manifiesta en la reiteración de los ataques, lo que lo diferencia del conflicto laboral puntual que puede surgir fruto de las tensiones que se generan en una relación laboral. Como señala el Tribunal Constitucional (STC 56/2019, de 6 de mayo), el acoso laboral "engloba situaciones o conductas muy diversas de estrés laboral que tienen de común que, por su reiteración en el tiempo, su carácter degradante de las condiciones del trabajo o la hostilidad que conllevan, tienen por finalidad o como resultado atentar o poner en peligro la integridad personal del empleado". En esta sentencia se señala que "los objetivos del acoso laboral pueden ser de lo más variado: represaliar a un trabajador poco sumiso, marginarle para evitar que deje en evidencia a sus superiores, infundirle miedo para promover el incremento de su productividad o satisfacer la personalidad manipulativa u hostigadora

\footnotetext{
${ }^{3}$ ALTÉS TÁRREGA, J. A. (2008), El acoso del trabajador en la empresa, Valencia: Tirant lo Blanch, pp. 12 y 13. También RODRIGUEZ INIESTA, G. (2006), El acoso laboral y su protección frente al mismo, en SÁNCHEZ TRIGUEROS, C. (Dir.) La presencia femenina en el mundo laboral: metas y realidades, Navarra: Thomson Aranzadi, 2006, p. 310 y 311.
} 
del acosador (el llamado acoso "perverso"), entre otros. Dentro de las organizaciones privadas el acoso laboral responde muchas veces al fin o resultado de que el trabajador hostigado abandone voluntariamente, ahorrando a la empresa la indemnización por despido improcedente, en las administraciones públicas, dadas las peculiaridades del régimen funcionarial, consiste a menudo en la marginación profesional del empleado por variados motivos (venganza personal, castigo encubierto, discriminación ideológica)".

Este ilícito, pese a su grave incidencia en las relaciones laborales, sigue sin tener, a diferencia del acoso sexual o los denominados acosos discriminatorios, un referente normativo especifico en el ordenamiento jurídico laboral, más allá del art. 4.2.e ET que establece el derecho del trabajador "al respeto de su intimidad y a la consideración debida a su dignidad", lo que lleva implícita la protección frente al acoso laboral, por mucho que no se incluya entre el resto de tipos de acoso que el precepto sí menciona: el acoso por razón de origen racial o étnico, religión o convicciones, discapacidad, edad u orientación sexual, y el acoso sexual y el acoso por razón de sexo. Dado que existe una tendencia a calificar estos otros acosos como una especie de acoso moral, resulta cuando menos paradójico que se haya regulado con anterioridad la especie que el géneró ${ }^{4}$.

Por ello, resulta plausible que desde la óptica del derecho penal se avanzara en la protección de este ilícito mediante su inclusión como un delito penal específico. Efectivamente, la reforma de la Ley Penal en 2010 (Ley Orgánica 5/2010, de 22 de junio) incluyó, tras algunos intentos anteriores frustrados, el delito de acoso laboral, en relación con las conductas que infringen un trato degradante. De forma previa estas conductas para ser castigadas debían reconducirse a otros delitos y faltas (lesiones, coacciones, amenazas, injurias, trato degradante, delitos contra los derechos de los trabajadores), lo cual requería acreditar, en lugar del acoso, los hechos integradores de los tipos supuestamente aplicables ${ }^{5}$, aunque son ciertamente escasas las sentencias que condenan en base a conductas de $\operatorname{acoso}^{6}$.

La inclusión del delito de acoso moral, como se ha señalado ${ }^{7}$, estuvo fuertemente influida por la normativa comunitaria y su preocupación por establecer una protección adecuada frente al acoso moral en el trabajo a través de un conjunto de normas muy heterogéneas que, si bien en un momento se centraban en el acoso sexual laboral, fueron tomando conciencia de la magnitud de este tipo de violencia, cuyas consecuencias trascienden a las propias víctimas, que sufren sus devastadores efectos, para afectar también a las empresas y al conjunto de la sociedad en general ${ }^{8}$.

Debe hacerse notar que el delito se ha encuadrado entre los que afectan a la integridad moral y no entre los delitos contra los trabajadores, lo que tiene sentido si se piensa que la conducta de

${ }^{4}$ La consideración del acoso moral o laboral como género y del resto de acosos como especie en estudios doctrinales laborales -LUELMO MILLAN, M. A. (2006), La normativa que viene sobre el acoso moral y sexual y las aportaciones doctrinales y jurisprudenciales más recientes a su tratamiento jurídico, Aranzadi social (12); PÉREZ DEL RÍO, M. T. (2006), La violencia de género en el trabajo: elementos conceptuales y recepción normativa, en DURÁN LÓPEZ, F., CRUZ VILLALÓN, J.; CASAS BAAMONDE, M. E. (Coord.), Las transformaciones del derecho del trabajo en el marco de la Constitución española: estudios en homenaje al profesor Miguel Rodriguez-Piñero y Bravo Ferrer-, Madrid: La Ley, p. 476.; LOUSADA AROCHENA, J. F. (2003), El acoso moral por razón de género, Aranzadi Social, (15), pp. 1243 y ss.; MOLINA NAVARRETE, C. (2019-a), ¿La cuestión de género muta hoy en «delito» la «broma» de ayer?: la (infra) valoración judicial de la violencia laboral contra las mujeres, Revista de Trabajo y Seguridad Social. CEF, (433), p. 225- y penales -OTERO GONZÁLEZ, P.; POMARES CINTAS, E. (2010), El acoso laboral (mobbing), en ÁLVAREZ GARCÍA, F. J.; GONZÁLEZ CUSSAC, J. L. (dirs.), Comentarios a la reforma penal de 2010, Valencia: Tirant lo Blanch, p. 202 y 203. Esta corriente también está presente en la doctrina judicial. Sirva de ejemplo la STSJMadrid, Social, de 11 de junio de 2007, n. 413/2007.

${ }^{5}$ SÁNCHEZ GARRIDO, J. A. (2011), La consideración penal del mobbing, Diario la Ley, (7612), p. 3/5.

${ }^{6}$ TRABADO ÁLVAREZ, C., (2011), La regulación penal del delito de mobbing en España, Diario La Ley, (7718), p. 1/16.

${ }^{7}$ BUSTOS RUBIO, M. (2013), El delito de acoso laboral: exigencias europeas y análisis del tipo penal, Revista de Derecho Penal y Criminología, (1), pp. 13-52.

${ }^{8}$ De hecho, desde la doctrina se ha hecho notar que el acoso laboral para la Unión Europea es sobre todo un problema económico que deja en segundo plano la defensa de la dignidad del trabajador —POMARES CINTAS, E. (2009), ¿Protección penal específica del derecho a no sufrir acoso en el trabajo?, en ÁLVAREZ GARCÍA, F. J. (Dir.), La adecuación del Derecho penal español al ordenamiento de la Unión Europea. La politica criminal europea, Valencia: Tirant lo Blanch, p. 290. 
acoso va más allá de la afectación a un derecho laboral específico, adentrándose de forma flagrante en el ámbito de la integridad moral del sujeto, y de su propia dignidad'.

En concreto, el art. 173.1 CP prescribe que "el que infligiera a otra persona un trato degradante, menoscabando gravemente su integridad moral, será castigado con la pena de prisión de seis meses a dos años" y, ya en el párrafo segundo, que, "con la misma pena serán castigados los que, en el ámbito de cualquier relación laboral o funcionarial y prevaliéndose de su relación de superioridad, realicen contra otro de forma reiterada actos hostiles o humillantes que, sin llegar a constituir trato degradante, supongan grave acoso contra la víctima".

En el primer párrafo se describe una conducta genérica, que puede llevar a cabo cualquier sujeto, en cualquier ámbito y que se constituye por la realización de un trato degradante que menoscaba gravemente la integridad moral de la persona.

En el segundo párrafo, partiendo de ese supuesto genérico, se describe una situación específica que, a mi juicio, presenta tres peculiaridades:

La primera, relativa al ámbito en que se realiza la conducta, que es el trabajo por cuenta ajena, tanto el propiamente laboral, como el funcionarial en las distintas administraciones públicas. La inclusión de las relaciones jurídico-publicas de carácter funcionarial es ciertamente positiva, puesto que en este ámbito el ilícito tiene una incidencia mayor ${ }^{10} \mathrm{y}$, al tiempo, ha evitado que en base al principio de legalidad y de la prohibición de analogía in mala partem el acoso en el sector público quede impune ${ }^{11}$.

La segunda, relativa al sujeto activo del delito que ha de ser necesariamente un superior jerárquico de la víctima.

Como puede observarse estas dos modalizaciones por sí mismas no aportan mucho al tipo general, pues, siendo la pena la misma, por mucho que se realicen por un sujeto en particular y en un ámbito determinado, estos comportamientos quedarían igualmente subsumidos en dicho tipo.

Sin embargo, es la tercera característica la que claramente establece una especialidad que individualiza el delito. El precepto se refiere a las conductas que, sin llegar a constituir un trato degradante, supongan un acoso grave. Por tanto, la modalización del delito lleva consigo que, ante conductas de menor gravedad, se aplique la misma pena y, en consecuencia, sí puede defenderse la existencia de un tipo penal singularizado referido al acoso laboral.

Pese a la inclusión de este delito hace más de una década y, pese a que los datos estadísticos demuestran una alta incidencia de estos comportamientos en el ámbito laboral, en proporción no son muchas las sentencias estimatorias que se han dictado en esta materia.

Esta situación admite diversas explicaciones. Por un lado, puede argüirse que la alta tasa de incidencia no tiene una correlación con el número de denuncias tramitadas, especialmente en el ámbito penal. Muchas de estas conductas no salen a la luz, porque las propias víctimas por temor a revelarlas las mantienen ocultas.

Por otro lado, seguramente, la complejidad probatoria que revisten estas conductas es otro factor a tener muy en cuenta en esta realidad. Al tratarse de conductas que muchas veces se realizan de forma privada, contar con los elementos de prueba suficientes para lograr una condena no siempre es tarea sencilla.

\footnotetext{
${ }^{9}$ BUSTOS RUBIO, M. (2013), ob. cit., p. 30.

${ }^{10}$ SANTANA VEGA, D. M. (2013), El nuevo delito de acoso laboral (versión en línea), en ÁLVAREZ GARCÍA, F. J.; COBOS GÓMEZ DE LINARES, M. A.; GÓMEZ PAVÓN, P. (coord.), Libro Homenaje al profesor Luis Rodríguez Ramos, Valencia: Tirant lo Blanch, p. 872, citando la STSJ-Madrid, Social, de 23 de enero de 2007, n. 61/2007; y BUSTOS RUBIO, M. (2013), ob. cit., p. 30. No obstante, algún autor matizaba estas afirmaciones y hacía ver como la seguridad laboral de los empleados públicos, que difícilmente pueden ser despedidos y el acceso a cauces de defensa es una clara diferencia con los trabajadores del sector privado —NÚNEZZ FERNÁNDEZ, J. (2010), Aspectos esenciales del nuevo delito de acoso laboral y sus antecedentes jurisprudenciales como trato degradante, Diario La Ley, (7534), p. 2/9

${ }^{11}$ BUSTOS RUBIO, M. (2013), ob. cit., p. 30.
} 
Finalmente, este panorama se puede explicar por la poca comprensión por parte de los órganos judiciales penales de estas conductas. Si, en ocasiones, puede resultar complicado diferenciar un conflicto laboral de un ilícito laboral de acoso, aún son mayores las dificultades para distinguir entre éste ilícito y el delito, lo que deriva en muchas sentencias absolutorias o en el archivo de actuaciones derivando la situación al orden jurisdiccional social ${ }^{12}$.

En las siguientes páginas se propone un análisis de este delito y de su alcance, que pretende introducir cierta concreción a la abstracción del código penal, así como introducir, cuando sea posible, criterios laborales compatibles, que posibiliten una interpretación más sensible a la realidad de este ilícito por parte de los jueces.

\subsection{La conducta penada}

Como se ha señalado, este delito se configura como un atentado a la integridad moral de la persona que se perfecciona mediante "actos hostiles o humillantes que, sin llegar a constituir trato degradante, supongan grave acoso contra la víctima", por lo que tiene su base, como el resto de supuestos del art. 173, en el art. 15 CE que establece que "todos tienen derecho a la vida y a la integridad fisica y moral, sin que, en ningún caso, puedan ser sometidos a tortura ni a penas o tratos inhumanos o degradantes".

La integridad moral y el trato degradante son conceptos, como determina el Tribunal Constitucional (STC 56/2019, de 6 de mayo), "lo suficientemente estrictos como para impedir la banalización del derecho fundamental reconocido $y$, al propio tiempo, lo suficientemente flexibles como para ajustarse a los problemas y condiciones de la vida actual (en este sentido, la STEDH de 28 de julio de 1999, asunto Selmouni c. Turquía, refiriéndose al art. 3 del Convenio europeo de derechos humanos), sin reducir la protección constitucionalmente garantizada a las relaciones con las fuerzas y cuerpos de seguridad y en las comisarias, las cárceles, los centros de acogida o las escuelas"; y esto ha permitido al Tribunal proyectar el art. 15 CE sobre el ámbito de las relaciones laborales, en particular sobre el acoso laboral (STC 74/2007, de 16 de abril; STC 106/2011, de 20 de junio; STC 81/2018; y STC 56/2019, de 6 de mayo).

\subsubsection{La integridad moral como bien jurídico protegido}

La STC 120/90, de 27 de junio, establecía que la garantía del derecho a la integridad física y moral “ protege la inviolabilidad de la persona no solo contra ataques dirigidos a lesionar su cuerpo o espiritu, sino también contra toda clase de intervención en esos bienes, que carezca del consentimiento del titular". Sobre esta base la jurisprudencia de la sala penal del Tribunal Supremo ha perfilado el concepto de integridad moral, estableciendo que el mismo "es un atributo de la persona, como ente dotado de dignidad por el solo hecho de serlo; esto es, como sujeto moral, en sí mismo, investido de capacidad para decidir responsablemente sobre el propio comportamiento. La garantía constitucional de la dignidad, como valor de la alta calidad indicada, implica la proscripción de cualquier uso instrumental de un sujeto y de la imposición al mismo de algún menoscabo que no responda a su fin constitucionalmente legitimo y legalmente previsto" (STS, Penal, de 3 de octubre de 2001, n. 175/2001). Configura un espacio propio de protección penal, "desde la idea de la inviolabilidad de la personalidad humana en el derecho a ser tratado como uno mismo, como un ser humano libre y nunca como un simple objeto, o si se prefiere, podria hablarse de la incolumidad personal o de su inviolabilidad' (STS, Penal, de 2 de noviembre de 2004, n. 1218/2004).

\footnotetext{
${ }^{12}$ En este sentido, SALVADOR CONCEPCIÓN, R. (2019), Responsabilidad del empleador como garante ante el acoso psicológico laboral, Revista Aranzadi de Derecho y Proceso Penal, (53), justifica esta situación en la gravedad exigida y en la severidad exigida para su punición.
} 
Bajo estos parámetros, se refiere la integridad moral "como aquel interés que tiene toda persona por ser respetada como tal, que conlleva el derecho a no ser sometida a comportamientos humillantes o que se dirijan a tal fin, y que además impide concebir a la misma como un mero instrumento en manos de otro sujeto, en respeto de su dignidad" 13 .

\subsubsection{El trato degradante como límite del acoso laboral}

La conducta que realiza el sujeto de acuerdo con el art. 173.1, párrafo segundo CP, no debe llegar a constituir un trato degradante ${ }^{14}$. Esto es, el tipo penal se define mediante lo que no es, lo cual no ayuda a configurar el delito ${ }^{15}$. Además, resulta sumamente abstracto, pues, si ya resulta difícil concretar qué es el trato degradante, más aún lo son aquellas conductas que, aproximándose, no llegan a constituirlo ${ }^{16}$.

El trato degradante, junto con la tortura y los tratos inhumanos "son, en su significado juridico, nociones graduadas de una misma escala que, en todos sus tramos, denotan la causación, sean cuales fueren los fines, de padecimientos físicos o psíquicos ilícitos e infligidos de modo vejatorio para quien los sufre y con esa propia intención de vejar y doblegar la voluntad del sujeto" (STC 120/1990, de 27 de junio). Estas intromisiones "constituyen un atentado «frontaly radical» a la dignidad humana "bien porque cosifican al individuo, rebajándolo a un nivel material o animal, bien porque lo mediatizan o instrumentalizan, olvidándose de que toda persona es un fin en si mismo»" (STC 181/2004, de 2 de noviembre; y STC 56/2019, de 6 de mayo).

Bajo estos parámetros, la jurisprudencia penal ha establecido que "lo que se pretende con la tipificación de este delito es reafirmar la idea de que el ser humano es siempre fin en sí mismo, sin que quepa "cosificarlo", circunstancia que obliga a distinguir los simples ataques a la integridad física o psíquica de aquellos otros con repercusión directa en la dignidad humana" (STS, Penal, de 18 mayo de 2016. 420/2016), describiéndolo como una conducta que crea "en las víctimas sentimientos de terror, de angustia y de inferioridad susceptibles de humillarle, de envilecerle y de quebrantar, en su caso su resistencia fisica o moral' (STS, Penal, de 29 de septiembre de 1998, n. 1122/1998).

\footnotetext{
${ }^{13}$ BUSTOS RUBIO, M. (2013), ob. cit., p. 29.

${ }^{14}$ De otra manera también se ha entendido que, si bien los actos de acoso individualmente considerados no alcanzan el trato degradante, en su conjunto sí lo serían "como parece dar a entender SERRANO ROMENO, J. F., (2011), Regulación legal del mobbing: laboral, administrativa, civil y penal. Especial referencia a la reforma penal operada en esta materia por LO 5/2001, Diario La Ley, (7650), p. 14; y MUÑOZ CONDE, F., (2019), ob. cit., p. 178, quien expresamente señala que "si lo que se tipifica en el acoso laboral o inmobiliario son conductas que por separado serían meras vejaciones leves atípicas, habrá que exigir al menos que por su carácter continuado alcancen un nivel de gravedad equiparable al trato degradante del párrafo primero del art. 173.1”. Sobre el tema también VILLACAMPA ESTIARTE, C. (2012), La incriminación del mobbing en Derecho penal español: los claroscuros del delito de acoso laboral, Revista de Derecho y Proceso Penal, (30), p. 47/54.

${ }_{15}$ DOLZ LAGO, M. (2018), El acoso ante el derecho: fronteras interdisciplinares, Diario La Ley, (9112), p. 4/31. Para CARMONA SALGADO, C. (2011), Tratamiento jurídico-penal de los acosos laboral, sexual, inmobiliario y escolar a raíz de la reforma de la LO 5/2010 (1), Diario la Ley, (7626), p. 1/10, el "texto contiene una clara contradicción legal, al exigir en términos genéricos que los actos «reiterados» de acoso no constituyan «trato degradante», pues difícilmente podrán éstos obviar ese requisito en tanto la reiteración y continuidad en la práctica de conductas hostiles o humillantes son, precisamente, los elementos esenciales que integran el segundo de esos conceptos, según opinión doctrinal y jurisprudencial mayoritaria. En todo caso, y para evitar futuros conflictos interpretativos, hubiera sido más acertado sustituir esa cláusula genérica de exclusión por la individualizada exigencia de requerir que sean los actos «aislados» de acoso los que no constituyan esa clase de trato”.

${ }^{16}$ MUÑOZ CONDE, F. (2019), Derecho penal, parte especial (22 ed.), Valencia: Tirant lo Blanch, Valencia, p. 178; y BUSTOS RUBIO, M. (2013), ob. cit., p. 34. Sin embargo, otros autores no comparten esta crítica, pues, además de que el Tribunal Supremo ha ido definiendo y concretando esos elementos, "esa amplitud en su definición ha contribuido a su estabilidad ya próxima a los 25 años de vigencia” - MUÑOZ CUESTA, J. (2020), Rechazo social al trato degradante como atentado a la integridad moral, Revista Aranzadi Doctrinal, (2), p. 2/9.
} 
Pues bien, El Tribunal Constitucional, para apreciar la lesión, requiere verificar si "la conducta enjuiciada es deliberada o, al menos, está adecuadamente conectada al resultado lesivo (elemento intención); si ha causado a la víctima un padecimiento fisico, psíquico o moral o, al menos, encerraba la potencialidad de hacerlo (elemento menoscabo) y si respondió al fin de vejar, humillar o envilecer o era objetivamente idónea para producir o produjo efectivamente ese resultado (elemento vejación)" (STC $56 / 2019$, de 6 de mayo). Estos requisitos han sido recogidos también en la práctica judicial penal, exigiendo a) un acto de claro e inequívoco contenido vejatorio para el sujeto pasivo del delito; b) un padecimiento físico o psíquico en dicho sujeto; y c) un comportamiento que sea degradante o humillante e incida en el concepto de dignidad de la persona afectada por el delito. Y en cuanto al resultado exige el precepto que el trato degradante menoscabe gravemente la integridad moral, lo que excluiría los supuestos banales o de menor entidad (STS, Penal, de 3 de marzo de 2009, n. 233/2009; STS, Penal, de 26 de octubre de 2009, n. 1061/2009), por lo que como puede observarse la sanción penal tiene un ámbito de aplicación más restringido, eliminando de la ecuación aquellas conductas que no se hayan perfeccionado como un acto inequívoco de valor vejatorio o hayan efectivamente causado un daño físico o psicológico al sujeto.

Ahora bien, en relación con el acoso laboral, nos situamos en un plano inferior. Nos referimos a conductas que se aproximan a las descritas, sin llegar a alcanzarlas. De hecho, si se calificaran como como un trato degradante, el tipo penal será el del art. 173.1, párrafo primero y no el específico del acoso laboral, aunque la pena en ambos casos es la misma. Ello, a su vez, suscita nuevas dudas sobre la configuración del delito, pues castigar dos delitos de diferente gravedad con la misma pena puede lesionar el principio de proporcionalidad. Ahora bien, debe tenerse presente que en el caso del acoso laboral se requiere una reiteración en la conducta que no se da necesariamente en el delito contra la integridad moral del primer inciso del art. $173.1^{17}$. De esta manera, la reiteración sería el elemento que igualaría en gravedad ambos delitos ${ }^{18}$.

\subsubsection{Los actos hostiles y degradantes como conducta perseguida}

Finalmente, la conducta se integra por la realización de "forma reiterada actos hostiles o humillantes que (...) supongan grave acoso contra la víctima".

El CP, para definir la conducta de acoso laboral, utiliza una formulación y terminología similar a las que contiene la Ley 62/2003, de 30 de diciembre, de Medidas Fiscales, Administrativas y del Orden Social y la Ley Orgánica 3/2007, de 22 de marzo, para la igualdad efectiva de mujeres y hombres en relación con el acoso sexual y los acosos discriminatorios, recogiendo, a su vez, los postulados de la normativa comunitaria que transponían.

\section{a) La reiteración de actos}

Como se acaba de referir el perfeccionamiento del tipo penal exige una reiteración de actos. Se requiere que el comportamiento se produzca en más de una ocasión, salvo, evidentemente, que se trate de un acto lo suficientemente grave como para constituir un trato degradante, en cuyo caso la conducta sería igualmente punible en base al art. 173.1 inciso primero CP.

\footnotetext{
${ }^{17}$ Efectivamente, en este delito se incluyen, tanto "aquellas conductas aisladas que por su naturaleza tienen entidad suficiente para producir un menoscabo grave de la integridad moral de la victima, cuando de aquellas otras que, si bien aisladamente consideradas no rebasarían el umbral exigido por este delito, sin embargo en tanto reiteradas o sistemáticas, realizadas habitualmente y consideradas en su conjunto, terminan produciendo dicho menoscabo grave a la integridad moral' (STS, Penal, de 2 de noviembre de 2004, n. 1218/2004).

${ }^{18}$ SANTANA VEGA, D. M. (2013), ob. cit. p. 874; BUSTOS RUBIO, M. (2013), ob. cit., pp. 35 y 36.
} 
Pues bien, parece claro que será labor de los tribunales determinar cuándo se produce esta reiteración. No obstante, la doctrina penal pone en el énfasis, más que en el número, en que los actos sean habituales y se prolonguen en el tiempo ${ }^{19}$; en la continuidad y permanencia de los mismos ${ }^{20} \mathrm{y}$ en la creación de un clima humillante que degrada la integridad moral de la víctima ${ }^{21}$. Este clima hostil y humillante hace referencia al acoso ambiental, que crea al trabajador una situación laboral intolerable, lo cual conlleva tanto repercusiones objetivas: la reducción del rendimiento, el absentismo laboral, como subjetivas: la sumisión del trabajador afectado a una alta presión psicológica ${ }^{22}$.

En cualquier caso la reiteración y persistencia de la conducta afecta a su gravedad, pudiendo llegar a convertir en graves conductas que de forma aislada se considerarían leves ${ }^{23}$.

En el ámbito laboral también se exige esta reiteración, aunque, en algunos casos, una conducta lo suficientemente grave debería ser bastante para activar los mecanismos de reparación laboral ${ }^{24}$, sobre todo si sus consecuencias se prolongan en el tiempo ${ }^{25}$. Este último criterio ha llevado a la doctrina penal a equiparar la situación humillante y degradante derivada de actos aislados con la reiteración de los mismos como ocurre con la decisión de destinar a un trabajador a la realización de tareas de una categoría inferior ${ }^{26}$.

b) El "grave acoso": ¿¿delito de resultado o de mera actividad?

Otra cuestión sobre la que debate la doctrina penal tiene que ver con el "grave acoso" que implica esta reiteración de conductas, en tanto que, si se concibe como resultado de las mismas daría lugar a un delito de resultado ${ }^{27}$, mientras que si se entiende como un elemento ya tipificado del delito ${ }^{28}$, implícito en la conducta reiterada del sujeto activo, nos encontraríamos ante un delito de mera actividad $^{29}$. El Tribunal Supremo se ha decantado por esta última opción, por cuanto "no se trata de que el menoscabo de la integridad moral sea consecuencia del trato degradante, sino que el trato degradante será delictivo siempre que menoscabe gravemente la integridad moral de la persona" (STS, Penal, de 24 marzo de 2017, n. 196/2017).

De esta manera, la expresión legal aludida, lo único que aportaría "es una nueva exigencia típica: tales actos, que ya son acoso, deben ser graves"30, siendo esta característica la que permite identificar al acoso laboral en sede penal frente al acoso laboral «genérico» ${ }^{31}$.

\footnotetext{
${ }^{19}$ CARMONA SALGADO, C. (2011), ob. cit., p. 2/10.

${ }^{20}$ SANTANA VEGA, D. M. (2013), ob. cit., 876; BUSTOS RUBIO, M. (2013), ob. cit., p. 37.

${ }^{21}$ VILLACAMPA ESTIARTE, C. (2012), ob. cit., p. $45 / 54$.

${ }^{22}$ ALTÉS TÁRREGA, J. A. (2008), ob. cit., pp. 39 y 40 El propio Tribunal Constitucional hace mención de este tipo de acoso, en su sentencia 224/1999, de 13 de diciembre, al entender en relación con el acoso sexual que "queda asi prohibido no sólo el acoso en el cual el sometimiento de la mujer o el hombre a tales requerimientos no queridos ni pedidos de empleadores o compañeros, se erige en un peligro de la estabilidad en el empleo, la promoción o la formación profesional o cualesquiera otra condiciones en el trabajo o en el salario, sino también el acoso sexual consiste en un comportamiento de carácter libidinoso no deseado por generar un ambiente laboral desagradable, incomodo, intimidatorio, ofensivo o humillante para el trabajador (...)".

${ }^{23}$ SERRANO ROMENO, J. F., (2011), ob. cit., p. 13/17

${ }^{24}$ Así lo insinué en relación con el acoso por razón de género en comparación con el acoso sexual -ALTÉS TÁRREGA, J. A. (2008), ob. cit., p. 36.

${ }^{25}$ Este sería el caso, por ejemplo, del ciberacoso laboral donde "el medio tiene la suficiente entidad por sí mismo, por su intensidad e inmediatez de difusión o propagación, y su permanencia en sí misma, en la web, para que de la sola conducta se derive tanto la gravedad necesaria (subyacente al elemento de repetición) como el poder de causar un dańo relevante a la "víctima», lo busque o no, lo consiga o no"-MOLINA NAVARRETE, C. (2019-b), Redes sociales digitales y gestión de riesgos profesionales: prevenir el ciberacoso sexual en el trabajo, entre la obligación y el desafío, Diario la Ley, (9452), p. 7/19.

${ }^{26}$ SANTANA VEGA, D. M. (2013), ob. cit., 876.

${ }^{27}$ SANTANA VEGA, D. M. (2013), ob. cit., p. 877.

${ }^{28}$ Como lo entienden OTERO GONZÁLEZ, P.; POMARES CINTAS, E. (2010), ob. cit., p. 201.

${ }^{29}$ En esta posición BUSTOS RUBIO, M. (2013), ob. cit., p. 38 y 39; y MUÑOZ CUESTA, J. (2020), ob. cit.,

${ }^{30}$ BUSTOS RUBIO, M. (2013), ob. cit., p. 38 y 39.

${ }^{31}$ VILLACAMPA ESTIARTE, C. (2012), ob. cit., p. 48/54; y BUSTOS RUBIO, M. (2013), ob. cit., p. 38 y 39.
} 
c) Tipos de conducta incluidos en el delito

Finalmente, en este punto hay que referirse al tipo de conducta, pues el acoso laboral puede configurarse mediante el ejercicio de determinados actos (amenazas, coacciones, ofensas, insultos), pero también mediante fórmulas más sutiles como vaciar de contenido la actividad laboral, asignar al trabajador de funciones de inferior categoría, aislándolo de sus cometidos o, directamente, no encomendándole ningún tipo de tareas. En este punto, es importante hacer notar que la ya citada STC 56/2019, de 6 mayo, vino a confirmar como un supuesto de acoso laboral contrario a la integridad moral protegida por el art. $15 \mathrm{CE}$ la prolongada inactividad profesional padecida por el recurrente.

Sin embargo, los primeros estudios sobre el delito de acoso laboral entendieron que el tipo penal manejaba un concepto más restringido. La doctrina penal califica el primer tipo de conductas como activas y como omisivas las segundas, determinando que "el principio de taxatividad y la literalidad del precepto impiden acoger la modalidad omisiva, toda vez que el delito habla de realizar actos" $^{32}$, al tiempo que, eso sí, elevan una petición para que el legislador, de lege ferenda, de cabida a los comportamientos omisivos.

Ahora bien, por un lado, no creo todos estos comportamientos tengan el carácter de omisivos, sobre todo si provienen de un superior jerárquico, puesto que el no dirigir la actividad, el no asignar tareas o el asignar otras distintas implican una decisión empresarial, es decir son actos empresariales contrarios al buen hacer. Incluso la decisión de ignorar por completo al trabajador implica un acto de dejación de funciones, más que una omisión de las mismas ${ }^{33}$.

Y, por otro lado, no parece que la práctica judicial haya optado por restringir las conductas punibles en el sentido manifestado por la doctrina. En este sentido, la SAP-A Coruña, de 30 de mayo de 2018, n. 184/2018, mantiene, citando la SAP-A Coruña, de 3 de abril de 2017, n. 172/2017, "que uno de los tratos más degradantes en el trabajo es el hacer el vacio cuando se hace con la intención de que la persona trabajadora lo abandone. De hecho en la práctica judicial y forense son numerosas las referencias que se hacen a las situaciones de vacio y ninguneo como lesivas para la dignidad y consideración de quien las padece". Otro ejemplo, puede encontrarse en el AAP-Bilbao, de 4 de julio de 2008, n. 586/2008, que rechaza la existencia de un acoso laboral, fundamentado, entre otros aspectos por dejar vacío de contenido el puesto de trabajo del recurrente, pero no por entender que esta conducta es ajena al tipo penal, sino porque este aspecto había sido ya resuelto en vía laboral, y se había desestimado al quedar acreditado que, contrariamente a lo sostenido en la demanda, sí había venido realizando una serie de tareas propias de su cargo; o en la SAP-Logroño, de 21 de enero 2016, n. 7/2016, que, aunque confirma la absolución de los demandados por un acoso laboral en el que se alegaba una persecución laboral para dejar vacía de contenida la actividad laboral del querellante, lo hace por entender que no concurren en los hechos alegados delito, por no revestir las decisiones tomadas se realizaran con el propósito de humillar o menoscabar su integridad.

\footnotetext{
${ }^{32}$ BUSTOS RUBIO, M. (2013), ob. cit., p. 38 y 39.

${ }^{33}$ En este sentido, sí defendí en cierta ocasión en relación con el acoso homófono que la conducta de un compañero ignorando por completo al trabajador homosexual, difícilmente podía ser como un acoso sexual, pero sí constituiría un acto discriminatorio - ALTÉS TÁRREGA, J. A. (2002), El acoso sexual en el trabajo, Valencia: Tirant lo Blanch, p. 95. Probablemente, una vez se ha deslindado el acoso sexual de los acosos discriminatorios, esta conducta podría considerarse como un acoso por orientación sexual, ya que ignorar a una persona de forma continua es una forma más de humillación.
} 


\subsection{El prevalimiento o superioridad laboral}

Se entiende como prevalimiento la situación en la que el sujeto activo se aprovecha para cometer el delito de las ventajas y prerrogativas que posee por el hecho de encontrarse en una posición de superioridad respecto a la víctima (STS, Penal, de 24 de noviembre de 2005, n. 1469/2005).

El CP la regula como una agravante genérica en distintos apartados del art. 22 (situación de superioridad, abuso de confianza, prevalimiento de cargo público, prevalimiento por razones de familia). En otros casos el prevalimiento funciona como una agravante específica del tipo básico, como ocurre en el art. 184.2 CP, al que más adelante me referiré, en relación con el acoso sexual. En cambio, en el art. 173.1, inciso segundo, el prevalimiento configura un supuesto específico de delito, que no puede por tanto darse sin dicha conducta.

Pues bien, la referencia al acoso realizado "prevaliéndose de su relación de superioridad" ha llevado a entender que sólo el acoso descendente, realizado por un superior jerárquico, da lugar al tipo punible. Sólo estaría penado, por tanto, el supuesto de acoso laboral más típico, también conocido por la acepción inglesa bossing, relegando al ámbito laboral, civil y, en su caso, administrativo el acoso entre iguales o el más infrecuente acoso ascendente en el que un que la víctima ostenta una categoría superior a la del acosador.

Ello, a juicio de la doctrina, estaría en consonancia con el principio de ultima ratio, subsidiariedad e intervención mínima penal, de manera que sólo se actuaría sobre las conductas más graves siendo estas las que se producen cuando la humillación o intimidación proviene de un superior jerárquico ${ }^{34}$. Sin embargo, para muchos autores, aunque admiten la limitación del tipo penal al acoso descendente, subrayan que parece desconocerse que esta grave humillación propia del acoso laboral puede darse también en otros tipos de acoso, especialmente los que realizan compañeros de trabajo, lo que les ha llevado a criticar la redacción del precepto y a abogar por una revisión del mismo que incluya el acoso laboral horizontal ${ }^{35}$.

Sin embargo, cabe otra interpretación. En su día defendí, en un estudio sobre el acoso sexual, que esta conducta en su manifestación como chantaje sexual se define principalmente como un acoso vertical en el que el sujeto activo detenta una posición jerárquica superior en la organización empresarial, pero que también constituye chantaje sexual el que cometen otros sujetos que, aun sin poseer una relación jerárquicamente superior, poseen el "poder" de influir en las condiciones de trabajo de la víctima, cono pueden serlo los clientes de la empresa, los representantes de los trabajadores y otros sujetos que, partiendo de una igualdad formal, sin un poder directivo directo, sí lo poseen de manera indirecta. En este último supuesto estarían los trabajadores que, bien por lazos familiares, afectivos u de otro tipo, tienen una vinculación especial con estos otros sujetos, lo que les permitiría chantajear sexualmente a la víctima sobre la base de que con sus informes pueden lograr que varíen sus condiciones laborales. En estos casos la posición del sujeto activo es prevalente a la del sujeto pasivo, lo que posibilita la presencia de una verticalidad material. Por tanto, como seńalaba en dicho estudio el chantaje sexual se definiría en todo caso como un acoso vertical, siempre que esta característica se entienda en un sentido amplio que abarque más posibilidades que las que se derivan de la situación de los trabajadores en el organigrama de la empresa ${ }^{36}$.

Pues bien, a esta misma conclusión llega parte de la doctrina penal, precisando que la solución pasa por entender que la superioridad que exige el tipo penal no se circunscribe a las de tipo jerárquico-formal, sino que incluye otras de naturaleza fáctica, circunstancial o meramente contex-

\footnotetext{
${ }^{34}$ SALVADOR CONCEPCIÓN, R. (2019), ob. cit.

${ }^{35}$ MUÑOZ CONDE, F. (2019), ob. cit., p. 178.

${ }^{36}$ ALTÉS TÁRREGA, J. A. (2002), ob. cit., pp. 129 y ss.
} 
tual $^{37}$. Así, el dominio o poder que pueden ejercer de facto ciertos trabajadores que están en igualdad jerárquica o incluso en una categoría inferior con el sujeto acosado -representantes de los trabadores y trabajadores, pero que tienen un vínculo (familiar, afectivo, amistoso ) con un superior que sí puede tomar decisiones y represalias que afecten a la víctima- no estaría proscrita por el Código Penal. El precepto se refiere a una superioridad, pero no la define en base a ninguna jerarquía. De hecho se señala que cuando esta norma ha pretendido establecer un tipo en base a esta jerarquía lo ha hecho expresamente, como ocurre en el art. 184.2 CP en relación al tipo agravado de acoso sexual al que nos referiremos más adelante, por lo que a sensu contrario el art. 173.1, párrafo segundo estaría permitiendo tanto la modalidad de superioridad jerárquica como cualquier otra de naturaleza fáctica, contextual o funcional ${ }^{38}$. Esta interpretación choca con el hecho de que en este precepto se habla de una "relación de superioridad", lo que tiende asimilarse con una superioridad orgánica, mientras que en el mencionado art. 184.2 se describe una "situación de superioridad" que se puede equiparar a una superioridad funcional o de hecho.

En cualquier caso, de existir relación jerárquica no podrá presumirse el prevalimiento, que deberá ser probado so pena de vulnerar el principio de presunción de inocencia ${ }^{39}$.

Fuera de estos casos el acoso ascendente u horizontal no podría canalizarse a través del art. 173.1, inciso segundo, pero nada obsta para que sea punible mediante el inciso primero del precepto, si bien en este caso sería exigible que la conducta sí constituyera un trato degradante. De esta manera, se cumpliría estrictamente con el principio de proporcionalidad: la gravedad que implica el prevalimiento, sea o no jerárquico, exime alcanzar un trato degradante, mientras que en ausencia de dicha superioridad sí se requiere el mismo.

\subsection{Tipos de acoso incluidos en el delito}

Hasta ahora hemos analizado el delito tomando como base el acoso laboral moral o mobbing, pero lo que ahora queremos plantear es si en el tipo penal caben otros acosos recogidos en la normativa laboral. Me refiero a los denominados acosos discriminatorios, pues el acoso sexual configura un delito específico que se trata a continuación.

Estos acosos fueron introducidos en España por dos normas que ya hemos mencionado. En primer lugar, la Ley 62/2003, cuyo art. 28.1 establece que constituye acoso "toda conducta no deseada relacionada con el origen racial o étnico, la religión o convicciones, la discapacidad, la edad o la orientación sexual de una persona que tenga como objetivo o consecuencia atentar contra su dignidad y crear un entorno intimidatorio, humillante u ofensivo".

Y, en segundo lugar, la Ley Orgánica 3/2007, que determina en su art. 7.2 que "constituye acoso por razón de sexo cualquier comportamiento realizado en función del sexo de una persona, con el propósito o el efecto de atentar contra su dignidad y de crear un entorno intimidatorio, degradante u ofensivo.

Como puede observarse la forma de regular estos acosos es muy similar, por cuanto todos ellos implican una específica forma de discriminar. En realidad conforman un único tipo de acoso que se matiza por la pertenencia de la víctima a un colectivo determinado y que, de alguna manera, han llevado a circunscribir al genérico acoso moral o acoso laboral a la conducta por la que el empresario desgasta la moral de un trabajador con un objetivo definido, normalmente forzar su dimisión.

\footnotetext{
${ }^{37}$ BUSTOS RUBIO, M. (2013), ob. cit., p. 41.

${ }^{38}$ SERRANO ROMENO, J. F., (2011), Regulación legal del mobbing: laboral, administrativa, civil y penal. Especial referencia a la reforma penal operada en esta materia por LO 5/ 2001, Diario La Ley, (7650), p. 12/17 y 13/17. En el mismo sentido se pronuncia NÚNEZZ FERNÁNDEZ, J. (2010), ob. cit., p. 3/9; y BUSTOS RUBIO, M. (2013), ob. cit., p. 43.

${ }^{39}$ SANTANA VEGA, D. M. (2013), ob. cit., p. 878; y también BUSTOS RUBIO, M. (2013), ob. cit., p. 45.
} 
De esta manera, las mismas conductas se clasifican en una u otra categoría en función del objetivo perseguido, bien sea discriminatorio o bien se persigan determinadas consecuencias laborales y dado que la redacción del art. 173.1, párrafo segundo no se decanta por ninguna de ellas hay que entender que las engloba todas. Es más, puesto que el art. 22.4 CP considera una circunstancia agravante "cometer el delito por motivos racistas, antisemitas u otra clase de discriminación referente a la ideologia, religión o creencias de la víctima, la etnia, raza o nación a la que pertenezca, su sexo, orientación o identidad sexual, razones de género, la enfermedad que padezca o su discapacidad', habría que entender los acosos discriminatorios integran dicha agravante en relación con el acoso laboral recogido en el art. 173.1, inciso segundo CP, lo que, a la postre, influirá en la determinación de le pena ${ }^{40}$.

\subsection{La exigencia judicial de la gravedad de la conducta}

Como he señalado anteriormente, uno de los aspectos más controvertidos y, sin duda, cruciales en relación con el delito de acoso laboral es el de su gravedad, como medida que separa el ilícito laboral del delito penal. El Tribunal Supremo ha señalado, en relación con el trato degradante, que la gravedad como elemento que permite situar la conducta en la órbita penal es un límite difuso que requiere un estudio individualizado caso a caso (STS, Penal, de 22 de febrero de 2005, n. 213/2005). Efectivamente, la conducta relevante es la misma tanto en el ilícito laboral, como en el delito penal. Por tanto, para diferenciar uno y otro se pone el acento en la intensidad y parece que los órganos judiciales penales tienen efectivamente un nivel de exigencia muy alto para calificar la conducta como delito. Se trata de una opción jurídica perfectamente válida, como señala el Tribunal Constitucional, una vez enmarcado el acoso laboral en los conceptos de trato degradante y lesión a la integridad moral de acuerdo con el art. $15 \mathrm{CE}$, "desde la perspectiva de la protección debida al trabajador hostigado, tales conceptos constitucionales representan un minimo insoslayable para el legislador que establece -y para el órgano judicial que interpreta y aplica- un concepto normativo de "acoso laboral». Ahora bien, el concepto de "acoso laboral» que establezca la legalidad ordinaria bien puede ser más amplio que los de "trato degradante» y lesión de la «integridad moral» ( $p$. ej., si el legislador quiere dispensar al trabajador más tutela de la resultante del art. 15 CE) o más estricto ( $p$. ej., si el legislador penal quiere castigar más severamente determinados comportamientos hostigadores)".

Ahora bien, quizás esta postura tan restrictiva merezca la pena ser revisada. Esta actitud estaba justificada cuando, antes de la introducción del delito, se tramitaba el acoso laboral como un trato degradante conforme al art. 173.1 CP, pues las conductas descritas en dicho precepto tienen un plus de gravedad respecto del acoso laboral, por lo que sólo se aplicaría a los casos más graves y patentes, lo que determinaba el sobreseimiento penal, sin perjuicio de las posible depuración dela conducta en la jurisdicción laboral (AAP-Sevilla, de 24 de enero de 2012, n. 28/2012; SAP-Castellón, de 14 de febrero de 2024, n. 98/2014).

Sin embargo, a partir del momento en que el art. 173.1, inciso segundo CP, no requiere que la conducta se perfeccione como un trato degradante el nivel de gravedad exigido hasta entonces no debería mantenerse. Pese a ello, como pone de relieve el AAP-Jaén de 18 de diciembre de 2012, n. 333/2012, ya en aplicación del art. 173.1, inciso segundo CP y se mantiene años después en el AAP-Jaén, de 7 de febrero de 2017, n. 80/2017, la concreción penal del acoso laboral requiere una "violencia psicológica extrema"; y aunque esta expresión ha sido utilizada para definir con carácter

\footnotetext{
${ }^{40}$ En este mismo sentido, MOLINA NAVARRETE -(2019-a), ob. cit., pp. 224 y 225- considera, comentando la SAP de Alicante, de 20 de noviembre, n. 392/2018, que, pese a que se trató el tema objeto de litigio exclusivamente como un acoso moral, en realidad atañía a un acoso moral por razón de sexo/genero, haciendo notar que en la realidad laboral la mezcla de estas dos modalidades de acoso es muy frecuente, y se debió aplicar la agravante de “acoso moral por razones de sexo-género" ex artículo 22.4 CP.
} 
general el acoso laboral ${ }^{41}$, lo cierto es que desde el punto de vista del derecho del trabajo se ha entendido de forma mucho más amplia que en el derecho penal. Da la impresión de que es necesario que se perfeccione una conducta muy grave, que provoque, a su vez, resultados igualmente muy graves en la víctima, obviando todas las actuaciones que escapan a uno de estos criterios. Coincido con la doctrina en que el principio de intervención mínima implica que sólo se sancionen los casos más graves de acoso sexual, pero no puede entenderse de forma tan radical que prácticamente evite toda actuación penal ${ }^{42}$.

En el ámbito laboral ocurría algo parecido. En un principio, para calificar el acoso moral se requería: a) intención de dañar; b) producción de un daño en la esfera de los derechos personales que se concreta en un daño o trastorno psíquico y c) su carácter complejo, continuado, predeterminado y sistemático (STSJ-Galicia, Social, de 6 de marzo de 2003, Rec. 290/2003 ${ }^{43}$ ). Sin embargo, esta caracterización ha variado con el tiempo. En este sentido, el elemento de la intencionalidad perdió peso en alguna sentencia y dejó de ser imprescindible, siendo suficiente que los efectos producidos contengan un ataque contra la dignidad de la persona que lo padece o se haya creado un entorno hostil, degradante o humillante (STSJ-Madrid, Social, de 11 de junio de 2007, Rec. 2197/2007). Sin embargo, otras sentencias seguían insistiendo en este aspecto del ilícito. La STC 81/2018, de 16 de julio, aunque continuaba esta línea restrictiva y mantenía la intencionalidad como elemento calificador del acoso, omitía la consecución de un daño a tales efectos. De esta manera, las subsiguientes decisiones de la doctrina judicial dejaban de ahondar en el resultado dañoso (STSJ-Castilla y León-Burgos, de 18 de febrero de 2019, Rec. 12/2019; y STSJ-Castilla-La Mancha-Albacete, de 25 de abril de 2019, Rec. 440/2018) y, aún otras, dejaban en un segundo plano ambos elementos señalando su carácter accidental o contingente (STSJ-Andalucía-Sevilla, de 4 de abril de 2019, Rec. 1012/2018). El paso definitivo lo dio el Tribunal Constitucional en sentencia 59/2019, de 6 de mayo, que para calificar el acoso laboral tiene en cuenta: "si la conducta enjuiciada es deliberada o, al menos, está adecuadamente conectada al resultado lesivo (elemento intención); si ha causado a la víctima un padecimiento físico, psíquico o moral o, al menos, encerraba la potencialidad de hacerlo (elemento menoscabo) y si respondió al fin de vejar, humillar o envilecer o era objetivamente idónea para producir o produjo efectivamente ese resultado (elemento vejación)". Por tanto, se verifica que en el acoso la intencionalidad y el daño no son determinantes, bastando probar la conexión de la conducta con el resultado y que sea idónea para producir un daño ${ }^{44}$. Estos criterios ya aparecen recogidos en la jurisdicción ordinaria (STSJ-Andalucía-Sevilla, Social, de 27 de noviembre de 2019, Rec. 2399/2018), por lo que hay que esperar que comience a resolverse conforme a ellos ${ }^{45}$.

Cierto es que en ocasiones los hechos carecen de relevancia penal, pues las conductas no pasan de discrepancias laborales en el marco de unas relaciones de trabajo poco armónicas (AAP-Jaén, de 7 de febrero de 2017, n. 80/2017). Ahora bien, en otras ocasiones, las conductas que dejan de perseguirse siguiendo esta corriente son más intensas y son igualmente archivadas, por ello la doctrina, en este caso laboral, celebra actuaciones como la de la SAP-Alicante, de 20 de noviembre de 2018, n. 392/2018, condenando por acoso laboral, en base a la declaración de la víctima, los comentarios

\footnotetext{
${ }^{41}$ El ejercer una violencia psicológica extrema de forma sistemática y recurrente forma parte de la que se considera la primera decisión del acoso laboral —Leymann H. (1996). La persecution au travail: Mobbing, París: Editions du Seuil.

${ }^{42}$ CARMONA SALGADO, C. (2011), ob. cit., p. 2/10 y 3/10.

${ }^{43}$ Vid. también STSJ-Galicia, Social, de 8 de abril de 2003, Rec. 518/2003; SJS Murcia-7, de 7 de mayo de 2003, Proc. 48/2003; STSJ-Navarra, Social, de 31 de marzo de 2005, Rec. 118/2005.

${ }^{44}$ Sobre el tema MOLINA NAVARRETE, C. (2019 c), La "des-psicologización” del concepto constitucional de acoso moral en el trabajo: ni la intención ni el daño son elementos del tipo jurídico, Revista de Derecho Social (86), pp. 119 y ss.; y YAGÜE BLANCO, S. (2020), ob. cit.

${ }^{45}$ Sobre esta evolución vid. PONS CARMENA, M. (2020), ob. cit., pp. 42 y ss.
} 
reiterados de un jefe de concina que desbordaban el marco de los que pueden considerarse socialmente tolerables que llevo a crear una ambiente de trabajo hostil y humillante ${ }^{46}$.

Sentencias como estas muestran el camino hacia una interpretación más flexible y acorde con la realidad de estas conductas, "con objeto de evitar la impunidad de aquellas conductas acosadoras que, pese a ser sólo de índole psicológica, merman gravemente la dignidad del trabajador, con terribles consecuencias para su salud y estabilidad, y ello aunque resulte verdaderamente difícil justificar la severidad y repetición de los agravios sufrido" ${ }^{47}$.

\section{El delito de acoso sexual}

El Código Penal, tras la reforma operada en el año 1995, como consecuencia de la promulgación de la Ley Orgánica 10/1995, de 23 de noviembre, recogió, por primera vez, en su art. 184 el delito de acoso sexual. La tipificación de la conducta no debe entenderse como consecuencia de una previa impunidad. Como se señaló al analizar el delito de acoso laboral, las conductas se punían mediante otras figuras delictivas ${ }^{48}$. Es más, este nuevo tipo penal se criticó precisamente por incluir una pena menor que la que seńalaban esos otros delitos aplicables, desnaturalizando las pretensiones feministas al respecto ${ }^{49}$.

Para la jurisprudencia penal el fundamento del delito se encuentra en la necesaria protección de la esfera íntima de la persona (art. 18.1 CE), como reflejo de su dignidad (art. 10 CE). En el ámbito laboral, junto a estos presupuestos, se implica, además, el derecho a no ser discriminado, entendiendo el acoso sexual como una fórmula de poder del hombre frente a la mujer ${ }^{50}$.

Hay que señalar que la redacción originaria del precepto no recogía el acoso sexual ambiental. El tipo penal no incluía ni la solicitud explícita de un comportamiento sexual, cuando entre los sujetos no existe prevalencia laboral, ni aquellos comportamientos en los que, si bien no existe una solicitud sexual, sí que se crea un entono sexualmente hostil ${ }^{51}$. A mi juicio, de acuerdo con la clasificación de los tipos de acoso sexual laboral que en su día realicé, ambos supuestos configuran un acoso sexual ambiental, ya que este se define la ausencia de "poder", entendido como la capacidad que tiene el acosador de influir en la voluntad de la víctima y sin restringirlo a la posición jerárquica que poseen los sujetos, de manera que en otro caso se debe categorizar la conducta como un acoso de intercambio ${ }^{52}$.

El caso es que, bien por efecto de estas críticas, bien por la escasa plasmación judicial del delito (una sola sentencia hasta abril de 1999) el delito de acoso sexual se reformó a raíz de la promulgación de la Ley Orgánica 11/1999, de 30 de abril, para introducir igualmente el acoso sexual ambiental. En este sentido, la Sentencia, Penal, de 7 de noviembre, n. 1460/2003, de 7 de noviembre declara, que el fundamento del denominado "acoso ambiental" radica en la necesidad

\footnotetext{
${ }^{46}$ MOLINA NAVARRETE, C. (2019-a), ob. cit., p. 225.

${ }^{47}$ SALVADOR CONCEPCIÓN, R. (2019), ob. cit.

${ }^{48}$ NARVÁEZ BERMEJO, M. A. (1998), Delitos contra los derechos de los trabajadores y la Seguridad Social, Valencia: Tirant lo Blanch, p. 89; y, en el mismo sentido, BOIX REIG, J. y ORTS BERENGUER, E. (1999), Consideraciones sobre la reforma de los delitos contra la libertad sexual, por la Ley Orgánica 11/1999, Actualidad Penal, (35), p. 671.

${ }^{49}$ OLAIZOLA, I. (1998), El delito de acoso sexual, Sentencias TSJ y AP, Pamplona: Aranzadi. Véase una exposición de estas críticas en LARRAURI, E. (1997), El nuevo delito de acoso sexual: una primera valoración, Cuadernos de Derecho Judicial, (7), pp. 178 y ss.; y SÁNCHEZ, E. y LARRAUI, E. (1999), El nuevo delito de acoso sexual y su sanción administrativa en el ámbito laboral, Valencia: Tirant lo Blanch, p. 13.

${ }^{50}$ Sobre el tema vid. In extenso ALTÉS TÁRREGA, J. A. (2002), ob. cit., pp. 26 y ss.

${ }^{51}$ SÁNCHEZ, E. y LARRAUI, E. (1999), ob. cit., p. 13. Sin embargo, en otros sectores, justificaban esta restricción sobre la base del principio de intervención mínima penal —NARVÁEZ BERMEJO, M. A. (1998), ob. cit., p. 90.

${ }^{52}$ ALTÉS TÁRREGA, J. A. (2002), ob. cit., p. 134 y ss.
} 
de dispensar de una mayor protección a quienes se encuentran en una relación laboral, docente o de prestación de servicios, "en donde las relaciones se enmarcan en un segmento de mayor riesgo a ser sometidas a tratos de naturaleza sexual por parte de sus potenciales hostigadores, en donde concurrirá de ordinario alguna situación de superioridad (pero que la ley no exige), siendo también posible su consideración típica cuando el acoso sexual se produzca en un cuadro de horizontalidad"53.

El nuevo tipo penal del art. 184 sobre el acoso sexual se desarrolla a través de tres apartados, de los cuales el primero configura el tipo básico, el segundo un tipo agravado y el tercero uno hiperagravado en atención a la situación de la víctima. Puesto que los tres tipos configuran una situación de acoso, en principio, la reiteración de la conducta, esto es su continuidad o habitualidad, como ya se señaló anteriormente en relación con el delito de acoso laboral, será una nota común a todos ellos, sin que ello obste, en mi opinión, y en la de ciertos analistas de la norma laboral, que sea igualmente aplicable el delito en situaciones aisladas de fuerte gravedad ${ }^{54}$.

\subsection{El tipo básico de acoso sexual}

Según reza el art. 184.1 CP "el que solicitare favores de naturaleza sexual, para sí o para un tercero, en el ámbito de una relación laboral, docente o de prestación de servicios, continuada o habitual, y con tal comportamiento provocare a la victima una situación objetiva y gravemente intimidatoria, hostil o humillante, será castigado, como autor de acoso sexual, con la pena de prisión de tres a cinco meses o multa de seis a 10 meses".

La referencia a una "situación hostil o humillante", conecta este este tipo delictivo con la noción laboral del acoso sexual ambiental que tradicionalmente ha sido definido mediante esta expresión. Ahora bien, el precepto liga la situación de acoso ambiental a la solicitud de favores de naturaleza sexual, por lo que es este comportamiento el que sigue rigiendo la aparición del ilícito penal. Por tanto, se recoge una visión parcial y muy restringida del acoso ambiental, pues las conductas que mayoritariamente configuran esta categoría, se llevan a cabo por comportamientos, distintos a la solicitud de favores sexuales, que tienen el efecto de producir un entorno sexual no deseado y humillante para la víctima, las cuales siguen sin ser objeto del delito de acoso sexual. A modo de ejemplo, puede citarse la SAP-Madrid, de 9 de julio de 2012, n. 310/2012. Dicha sentencia resuelve sobre un caso en el que el que un oficial de farmacia se había dirigido de forma libidinosa a una auxiliar y a una farmacéutica adjunta. A una de ellas le había propinado dos palmadas, un beso en la oreja y un abrazo, le había propuesto una siesta en un hotel cercano y le había enviado contenido erótico desde su móvil; a la otra, aprovechando un descuido, le dio un beso en los labios, le acariciaba la pierna o el pelo y rozaba intencionadamente su cuerpo con el de ella. La audiencia entendió que sólo la proposición de hacer una siesta se configuraba como una solicitud sexual y que no era lo suficientemente grave como para dar lugar a un delito de acoso, aunque sí podrían haber dado lugar a otro delito como el de abusos sexuales ${ }^{55}$.

\footnotetext{
${ }^{53}$ También STS, Penal, de 22 de octubre, n. 721/2015. Sin embargo, hubo críticas a esta inclusión, señalando que la reforma de 2010 debería haber suprimido este tipo y dejar sólo el acoso sexual vertical — OTERO GONZÁLEZ, P.; POMARES CINTAS, E. (2010), ob. cit., pp. 202-203; y CARMONA SALGADO, C. (2011), ob. cit., p. 4/10, quien la califica como "infracción de bagatela".

${ }^{54}$ En este sentido, DOLZ LAGO, M. (2018), ob. cit., p. 5/31. El autor hace mención de la Instrucción n. 10/2005, de 6 de octubre de 2005, sobre el tratamiento del acoso escolar desde el sistema de Justicia Juvenil, que aboga por esta interpretación para no dejar fuera del acoso hechos aislados graves.

${ }^{55}$ Sobre esta sentencia SOTO SUÁREZ, C. (2013), Supuesto de acoso sexual o el cuidado con las palabras el Código Penal frente al diccionario de la lengua, Diario la Ley (8019).
} 


\subsubsection{La acción de acoso punible: la solicitud sexual}

Por otro lado, la caracterización de la "solicitud" ha llevado a la doctrina a las siguientes conclusiones.

$\mathrm{Al}$ igual que ocurre en el ilícito laboral, la conducta punible puede expresarse de múltiples maneras, pero, en cualquier caso, la misma debe ser clara y sin ambigüedades, no bastando la mera insinuación ${ }^{56}$. Puede darse de forma explícita o implícita, pero debe manifestarse de manera inequívoca (STS, Penal, de 22 de octubre de 2015, n. 721/2015). En consecuencia, no es necesario que se manifieste de forma verbal, basta que se exteriorice de manera que pueda ser entendida por la persona destinataria (STS, Penal, de 26 de abril de 2012, n. 349/2012; STS, Penal, de 28 de noviembre de 2014, n. 830/2014.

Por otro lado, "tampoco naturalmente es preciso que se traduzca en actos de abuso o agresión sexual, propiamente delictivos en otros apartados del mismo Título, pues de concurrir con el acoso sexual nos encontrariamos ante un concurso de normas que se resolvería ordinariamente por el principio de consunción" (STS, Penal, de 7 de noviembre de 2003, n. 1460/2003; y STS, Penal, de 22 de octubre de 2015, n. 721/2015). De esta manera, se zanja el debate doctrinal que enfrentó a quienes mantenían esta posición ${ }^{57}$ y quienes defendían que la solicitud de favores sexuales debía estar necesariamente en conexión con los comportamientos que constituyen delitos contra la libertad sexual, lo que derivaba en la exigencia de que en la conducta existiese o se pretendiese un contacto físico $^{58}$. Esta visión es, desde luego, mucho más cercana al concepto laboral de acoso sexual laboral y, en mi opinión, más acertada, pese a que algún autor ha manifestado que con ella se corre el peligro de sancionar proposiciones sexuales que, por su escasa identidad, contravendrían el principio de intervención mínima ${ }^{59}$.

Por último, al igual que ocurre en el ilícito laboral, una sola proposición que resulte seria y creíble a los ojos del sujeto pasivo puede dar lugar al delito ${ }^{60}$. Se introduce, de esta manera, un elemento subjetivo de apreciación del delito, similar al que ha presidido durante mucho tiempo la concepción del ilícito laboral, en base al cual éste sólo se perfecciona cuando, efectivamente, la conducta resulta ofensiva para la víctima, esto es, tiene el efecto de crear un clima indeseado, hostil y humillante. Sin embargo, esta manera de entender el ilícito favorece que determinadas conductas no puedan calificarse como acoso; que se enjuicie la moralidad de la víctima; y que sea necesario que esta muestre su rechazo, es decir, que ponga en conocimiento del sujeto activo el carácter indeseado de sus actos. Por ello, para corregir esta visión se introdujo un elemento objetivo ${ }^{61}$, en base al cual la existencia del acoso se supedita al conocimiento, expreso o presunto, de que la conducta del autor es ofensiva para la víctima. Se trata de introducir un parámetro, elaborado a partir del sentir

${ }^{56}$ En este sentido NARVÁEZ BERMEJO resalta que se necesita una petición -verbal o escrita, explícita o implícita- concreta de contenido erótico - Delitos contra..., ob. cit., p. 91.

${ }^{57}$ LARRAURI, E. (1997), ob. cit., p. 195; SÁNCHEZ, E. y LARRAURI, E., (1999), ob. cit., p. 17; OLAIZOLA, I (1998), ob. cit., p. 25.

${ }^{58}$ En este sentido MORALES PRATS, F. y GARCÍA ALBERO, R. (1996), Comentarios al art. 184, en QUINTERO, G. (dir.), Comentarios a la parte especial del Derecho Penal, Pamplona: Aranzadi, p. 900; y BOIX REIG, J. y ORTS BERENGUER, E. (1999), ob. cit., p. 679. En sentido contrario se señalaba que el delito requiere un inequívoco significado sexual, "con el que el favor solicitado sea objetivamente idóneo para excitar el instinto sexual de una persona, según los estándares de la comunidad, y ello con independencia de que el requerimiento se concrete o no en un acto que exija contacto físico" - Cfr. MATALLÍN EVANGELIO, A. (2000), El nuevo delito de acoso sexual, Valencia: Ediciones Revista General de Derecho, pp. 41 y 42

${ }^{59}$ NARVÁEZ BERMEJO, M. A. (1998), ob. cit., p. 91

${ }^{60}$ MATALlíN EVANGELIO, A. (2000), ob. cit., pp. 43 y 44. No obstante, a juicio de NARVÁEZ BERMEJO, con ello se contradice el concepto de acoso, pues éste necesita de una cierta insistencia para que se consume - Delitos contra..., ob. cit., p. 92.

${ }^{61}$ Así, por ejemplo, la definición del acoso sexual y acoso por razón de sexo de la Ley orgánica de igualad eluden caracterizarlos como actos no deseados que sí está presente en la normativa comunitaria. Sobre el tema vid. ALTÉS TÁRREGA, J. A. (2008), ob. cit., p. 29. 
social existente, que determina que conductas son atentatorias contra la dignidad personal. Bajo esta concepción se abre un amplio nivel de discrecionalidad para el juzgador que sería el encargado de fijar el estándar objetivo de acoso sexual, lo que puede llevar a desconocer que, en un momento dado, determinadas circunstancias de la víctima podrían hacer aparecer el ilícito donde en un contexto normal no lo haría. Por ello, ambos criterios actúan de forma complementaria ${ }^{62}$. Esta doble concepción del acoso fue recogida por la STC 224/1999, de 13 de diciembre. En esta sentencia, se establece que la normativa, además del acoso sexual típico o chantaje sexual, protege también contra aquél que "consiste en un comportamiento de carácter libidinoso no deseado por generar un ambiente laboral desagradable, incomodo, intimidatorio, ofensivo o humillante para el trabajador (...). En tal situación constituye un elemento esencial que esa conducta sea lo suficientemente grave como para crear tal entorno negativo y lo sea, por otra parte, no sólo según la percepción subjetiva o la sensibilidad particular de quien lo padece, sino objetivamente considerada".

De esta manera, si la proposición es lo suficientemente grave, no requerirá reiteración, ni que la víctima demuestre el carácter indeseado u ofensivo de la misma, por el contrario, aquellos comportamientos que pueden ser considerados como socialmente aceptables sí requerían la concurrencia de estos dos requisitos para dar lugar al delito.

\subsubsection{La relación laboral, docente o prestación de servicios como ámbito configurador del delito.}

El precepto caracteriza la relación laboral, docente y de prestación de servicios en cuyo ámbito sucede el delito con las notas de continuidad y habitualidad.

Pues bien, en primer lugar, la mención a la relación de prestación de servicios permite incluir en la sanción del acoso sexual conductas que, por desarrollarse fuera de los márgenes estrictos de lo que se conoce por Derecho del Trabajo, podrían haber quedado impunes (trabajadores autónomos, funcionarios, personal estatutario, personal militar $)^{63}$.

Y, en segundo lugar, debe manifestarse la crítica acogida que ha tenido la inclusión de las notas de continuidad y habitualidad en la caracterización de la relación. En este sentido, se ha dicho que "a lo más que puede llegarse, en el intento de precisar al máximo este elemento típico, es subrayar la necesidad de que la relación que obligue a sujeto activo y pasivo a encuentros frecuentes, en el seno de los cuales sea verosímil la creación de la situación descrita en el art. 184.1; parece igualmente necesario que ambos trabajen o estudien en el mismo centro (si lo hicieran en empresas u organismos diversos, se antoja menos probable el surgimiento de aquella situación); y que los encuentros supongan una suerte de convivencia, algo que podrá predicarse de alumnos de un mismo centro que se ven todos los días, etc. Es preciso, pues, que haya un roce casi cotidiano, para que pueda producirse una situación objetiva y gravemente intimidatoria, hostil o humillante, que es el tercer elemento de esta primera figura delictiva del artículo 184 " 44 .

${ }^{62}$ Sobre el tema ampliamente ALTÉS TÁRREGA, J. A. (2002), ob. cit., pp. 116 y ss.; y ALTÉS TÁRREGA, J. A. (2008), ob. cit., p. 29 y ss.

${ }^{63}$ Así la STS, Penal, de 7 de noviembre de 2003, n. 1460/2003, calificó como acoso laboral el ocurrido entre un alcalde y una concejala en una corporación municipal. En este mismo sentido, la STS, Penal, de 22 de octubre de 2015, n. 721/2015, entiende que una corporación local "satisface las exigencias del tipo penal, pues tal relación de servicios tiene que ser interpretada en el sentido de relación docente, laboral o afin a la misma, siendo meridianamente claro que la corporación municipal produce en su conjunto servicios públicos de incuestionable vocación continuada, incluso con rango constitucional, por lo que el requisito ambiental en donde se desarrollaron los hechos queda patentemente cumplido"; y más adelante que concurre manifiestamente el tipo básico, "pues el acoso se realizó en el ámbito de una relación laboral continuada, al ser el agresor y la víctima compañeros en una unidad policial de la Guardia Civil".

${ }^{64}$ BOIX REIG, J. y ORTS BERENGUER, E. (1999), ob. cit., p. 678. 


\subsubsection{Las consecuencias que ha de sufrir la víctima para exista delito}

Además, no sólo es necesario que haya una solicitud sexual, sino que la misma debe "provocar a la víctima una situación objetiva y gravemente intimidatoria, hostil o humillante".

Para la jurisprudencia penal, "la ley penal con este aspecto se refiere a un doble requisito: de un lado, una situación objetiva, pues no bastan meras impresiones al modo de una mera caracterización personal de la victima; de otro, y como resultado delictivo que indiscutiblemente requiere el tipo penal (STS, Penal, de 7 de noviembre de 2003, n. 1460/2003; STS, Penal, de 22 de octubre de 2015, n. $721 / 2015)$. Respecto del adverbio gravemente esta misma jurisprudencia establece que "se predica tanto de la situación intimidatoria, como de la hostil o humillante".

La doctrina penal resaltó el peligro que puede entrañar esta forma de calificar la conducta, pues, aunque el acoso sexual siempre crea un ambiente ingrato y degradante, no siempre provoca una situación objetiva y gravemente intimidatoria. Para esta doctrina, el acoso entre iguales no suele genera una situación de este tipo y, cuando lo hace, la conducta configurará un supuesto de tentativa del delito de agresión sexual del art. 178 que, específicamente, prevé la intimidación como medio comisivo, sin exigir, por otro lado, la gravedad ${ }^{65}$. Sin embargo, a mi juicio, el hecho de que se exija la "solicitud de favores sexuales" hace que este tipo penal se perfeccione siempre de forma más grave que la que se deduce del acoso ambiental común al que entiendo que se refiere esta doctrina.

Ciertamente, en el ámbito laboral, la doble concepción objetivo-subjetiva del acoso sexual permite castigar todas las conductas de acoso y no sólo las que crean una situación objetiva y gravemente intimidatoria, pero entiendo que la razón de ser de esta exigencia se encuentra probablemente en el antes mencionado principio de intervención mínima del Derecho Penal. Así lo ha mantenido el propio Tribunal Supremo, para el que esta exigencia "servirá en consecuencia para delimitar cuándo las características de la acción desbordan las previsiones protectoras del ordenamiento civil o del laboral, y se adentra el comportamiento desplegado en el ámbito de lo penal" (STS, Penal, de 7 de noviembre de 2003, n. 1460/2003). De esta manera, se han intentado resaltar en el precepto las necesarias notas de realidad y entidad de la situación, de manera que sólo se penalice que someta al sujeto pasivo en un clima realmente insoportable y no meramente incómodo ${ }^{66}$.

Finalmente, otra consecuencia que la jurisprudencia deduce de esta configuración es que " $n o$ es éste, en consecuencia, un delito de mera actividad o de resultado cortado (lo que producirá la concurrencia, en su caso, de formas imperfectas de ejecución), pues exige que se provoque en la víctima una situación gravemente intimidatoria, hostil o humillante" (STS, Penal, de 7 de noviembre de 2003, n. 1460/2003; STS, Penal, de 22 de octubre de 2015, n. 721/2015).

${ }^{65}$ SÁNCHEZ, E. y LARRAUI, E. (1999), ob. cit., p. 21. Se critica en este sentido la postura de algunos penalistas que han llegado a exigir para que nazca el delito de acoso sexual "una situación que objetivamente pueda calificarse como una amenaza, un atentado contra la integridad moral o una injuria grave" —cfr. MUÑOZ CONDE, F., (2019), ob. cit., p. 230—, pues, ciertamente, en estos supuestos la existencia de otros delitos que engloban estas conductas haría innecesario el de acoso sexual.

${ }^{66}$ BOIX REIG, J. y ORTS BERENGUER, E. (1999), ob. cit., p. 678. Ahora bien, ello provoca el problema de deslindar "la creación de una situación intimidatoria de la tentativa de agresión también intimidatoria. Deslinde que habrá de hacerse atendiendo al dato de inmediatez, de la concurrencia del intento de materializar una acción sexual y el empleo de intimidación, en cuyo caso estaremos ante una agresión; mientras que si lo que se origina es una atmósfera más o menos duradera, dentro de la cual se hostiga a la víctima, sin llegar a despojarla ni a limitar seriamente su libertad de decisión, poniéndola ante la disyuntiva de acceder a las exigencias del sujeto activo o de sufrir un mal grave e injusto estaremos ante un acoso sexual” - ibídem, pp. 678 y 679. 


\subsection{El tipo agravado}

En segundo lugar, el art. 184.2 prevé que "si el culpable de acoso sexual hubiera cometido el hecho prevaliéndose de una situación de superioridad laboral, docente o jerárquica, o con el anuncio expreso o tácito de causar a la victima un mal relacionado con las legítimas expectativas que aquélla pueda tener en el ámbito de la indicada relación, la pena será de prisión de cinco a siete meses o multa de 10 a 14 meses".

Se trata, precisamente, del tipo penal único de acoso sexual existente antes de la reforma del precepto en 1999. Las características a destacar en el mismo serían las siguientes.

\subsubsection{La conducta delictiva}

La conducta que hace nacer el delito sigue siendo la solicitud de favores sexuales y la creación de una situación objetiva y gravemente intimidatoria. Así hay que entender la implícita remisión que en este apartado se hace al anteriormente citado art. 184.1. Se trata, en definitiva, de una prolongación de la configuración inicial del delito, constituyendo una modalidad agravada del mismo ${ }^{67}$.

De esta manera, tampoco aparece castigado aquí el acoso sexual llevado a cabo por el empresario que no se concrete en una conducta de este tipo, como lo son determinados tipos de acoso sexual ambiental perpetrados por el empresario que, no obstante, la doctrina consideró que podrían llegar a incardinarse en el ámbito de aplicación del delito del art. 314 CP contra los derechos de los trabajadores ${ }^{68}$.

Por otro lado, no basta con que se dé la solicitud sino que la conducta aparece condicionada a la existencia de dos elementos que se configuran de forma alternativa y no acumulativa: el prevalimiento de una situación de superioridad laboral, docente o jerárquica o el anuncio expreso o tácito de causar un mal a la víctima ${ }^{69}$.

a) El prevalimiento laboral, docente o jerárquico

El artículo 184.2 CP en cambio, configura otro supuesto de prevalimiento como agravante específica, por lo que también en este caso el prevalimiento ha de ponerse en contexto para determinar en qué consiste.

Pues bien, en este sentido, hay que hacer notar que la referencia a un prevalimiento jerárquico sustituyó en la reforma de 1999 a la situación de prevalimiento "análoga" a la laboral o docente presente en la redacción anterior.

La concreción del significado del prevalimiento laboral está en íntima relación con el concepto de prevalimiento jerárquico. Así, para algunos autores la forma de redactarse el precepto denota que sólo puede ser sujeto activo de este delito quien está en una situación orgánica de superioridad laboral, es decir sólo se admitirían las formas de jerarquía stricto sensu. Sin embargo, a mi juicio, debe admitirse igualmente, por los motivos esgrimidos anteriormente al analizar el delito de acoso laboral, la jerarquía funcional, esto es la que pueden poseer por determinadas circunstancias ciertos

\footnotetext{
${ }^{67}$ BOIX REIG, J. y ORTS BERENGUER, E. (1999), ob. cit., p. 679.

${ }^{68}$ ALTÉS TÁRREGA, J. A. (2002), ob. cit., p. 191; y, SÁNCHEZ, E. y LARRAURI, E. (1999), ob. cit., p. 22, desde la perspectiva de que cualquier acoso sexual en el que no aparezca un requerimiento a la víctima de naturaleza sexual debe ser considerado como acoso sexual ambiental.

${ }^{69}$ Sin embargo, parte de doctrina entiende que sólo quien está en una relación de superioridad puede condicionar la voluntad de la víctima mediante el anuncio de truncar una expectativa legitima en el marco de alguna de las relaciones descritas, por lo que estos requisitos se exigen de forma acumulativa -BOIX REIG, J. y ORTS BERENGUER, E. (1999), ob. cit., p. 680. En contra MATALLÍN EVANGELIO, A. (2000), p. 53 y ss.
} 
sujetos que no poseen dicha superioridad orgánica, como los representantes de los trabajadores o las personas con una relación de afinidad con quienes pueden tomar las decisiones ${ }^{70}$. Nótese además que el precepto alude a una "situación" de superioridad laboral y no de "relación" de superioridad laboral, como se dijo que ocurre en el delito de acoso laboral.

De esta manera, se estaría puniendo la acción de prevalecerse de una situación de superioridad en una relación laboral y docente, independientemente de que se ocupe una categoría orgánicamente superior y, ahora sí, la acción de prevalerse de cualquier otra situación en la que exista una relación de jerarquía, lo que permite incluir otros supuestos (militares, médicos o comunidades terapéuticas, comunidades religiosas o servicios sociales). En cualquier caso, pese a la ausencia de requisitos formales para entender la existencia de esta relación jerárquica, surge la duda sobre si las relaciones familiares, o de gran diferencia de edad o las que se producen por una situación de dependencia económica son o no son relaciones jerárquicas ${ }^{71}$.

b) El anuncio expreso o tácito de causar un mal relacionado con las legítimas expectativas de la víctima

Por otro lado, también se consuma el delito mediante el anuncio de un perjuicio expreso o tácito ${ }^{72}$ a la víctima que afecte a sus expectativas en el entorno laboral docente o jerárquico en el que se desarrolle la relación. Se trata de poner a la víctima en una posición de debilidad que condicione su voluntad a la hora de resistirse, al crearle la convicción de que en otro caso el mal anunciado se consumarán ${ }^{73}$.

En el marco de una relación laboral, el daño debe concretarse sobre las expectativas legítimas que el trabajador tenga en relación con su empleo. La unión de estos dos términos puede resultar un tanto contradictoria, pues el término "expectativa" se refiere a un suceso incierto, sobre el que no se posee un derecho para forzar su realización. Se trataría de algo jurídicamente intangible, que hubiera sido prometido por el empresario. Por el contrario, en el término "legítimo" se incluyen aquellos derechos que el trabajador puede exigir por encontrase recogidos en el contrato, en el convenio colectivo o en la normativa laboral. La doctrina se decanta por entender que la expresión legítima se usa no en un sentido propio, "sino para acentuar un cierto grado de certidumbre en esa mejora de las condiciones laborales del trabajador". Como se señala, "siendo la expectativa una mera probabilidad de obtener un derecho si se cumplen ciertas condiciones, el mal con el que se podría amenazar el empresario al formular su solicitud pudiera consistir en negar una mejora de sueldo o ascenso no reglado, pero que dependería de la voluntad del empresario, convirtiendo la amenaza en un concepto vaporoso. Difícilmente se podría hablar de mal cuando a una persona se le priva de algo que no le corresponde o a lo que no tiene derecho. Incluso podría dudarse del poder seductor de una proposición cuando la víctima no desconoce la inseguridad de sus expectativas laborales,

${ }^{70}$ En este sentido, en consonancia con lo aquí señalado, la doctrina penal describe el acoso quid pro quo como "un supuesto de abuso de autoridad, por lo que sólo puede ser realizado por quien tenga poder para proporcionar o retirar un beneficio laboral", sin aludir a una posición orgánica superior - BARRANCO GÁMEZ, J. M., (2016), Acoso sexual, Diario la Ley, (8749), p. 7/14.

${ }^{71}$ SÁNCHEZ, E. y LARRAUI, E. (1999), ob. cit., p. 23. La doctrina venía a entender que este tipo de relaciones, se introducían en la redacción original como relaciones análogas -CARMONA SALGADO, C. (1996), Comentario al art. 18, en COBO DEL ROSAl M. (Dir.), Curso de Derecho Penal Español. Parte Especial I, Madrid: Marcial Pons, p. 332. Otros sectores se decantaban de forma más restrictiva por entender que debían concurrir relaciones de superioridad de la que dependerían (de forma análoga) legítimas expectativas -LAMARCA, C. (1996), La protección de la libertad sexual en el nuevo Código Penal, Jueces para la Democracia, (27), p. 60; y ORTS BERENGUER, E. (1996), Comentario al art. 184, en VIVES ANTÓN, T. (coord.) comentarios al Código Penal de 1995, Valencia: Tirant lo Blanch, p. 953.

${ }^{72}$ Se ha dicho que la inclusión de la forma tácita es un tanto desconcertante, ya que "si el anuncio del mal no es diáfano no puede pensarse en su credibilidad, ni tan siquiera en su existencia -Cfr. NARVÁEZ BERMEJO, M. A. (1998), ob. cit., p. 94.

${ }^{73}$ NARVÁEZ BERMEJO, M. A. (1998), ob. cit., p. 94. 
faltando el requisito de la seriedad o firmeza de la amenaza representada por el mal en que consiste para que produzca la necesaria conmoción o intimidación en el amenazado" ${ }^{74}$.

Asimismo, provocar un "mal" lícito del que se hace un uso ilícito también configura la aparición del delito, como sería, por ejemplo, condicionar la conducta del trabajador afectado por el acoso a no hacer uso de una causa de despido justa ${ }^{75}$.

En relación con el anuncio de un "bien", sólo queda incluido en el tipo cuando el sujeto acosado tiene una expectativa legítima, pues prometerlo a cambio de un favor sexual anuncia su no consecución en caso de negativa. Por el contrario, si no se tiene ninguna expectativa el ofrecimiento de un bien no esconde la amenaza de un mal por lo que no queda integrado en el delito ${ }^{76}$.

En cualquier caso, el "mal" con el que se amenaza no puede ser, a su vez, constitutivo de delito pues ello implicaría la aplicación del artículo 169 del Código Penal. No obstante, el daño sí puede constituir una falta como sería una vejación injusta de carácter leve o el desmerecimiento de su buena reputación como trabajador-STS, Penal, de 18 de septiembre de 1986 (RJ 4680)_ ${ }^{77}$.

No se ha resuelto, sin embargo, en la nueva redacción el problema de que el daño se concrete sobre una persona distinta a la víctima pero cuya relación con la misma puede condicionarla a aceptar la conducta (por ejemplo se amenaza con despedir al marido de la trabajadora) en cuyo caso el delito no sería aplicable ${ }^{78}$.

\subsubsection{Los sujetos del delito}

De acuerdo con lo señalado anteriormente, el sujeto activo del delito puede ser cualquier persona que ostente superioridad funcional laboral sobre la víctima y que se prevalezca de ella, así como cualquiera que anuncie un mal sobre las legítimas expectativas de la víctima.

De esta manera, en el marco de una relación laboral, el delito no se restringe al empresario persona física o a los administradores o representantes de la empresa, así como a los directivos y demás mandos jerárquicamente superiores, sino que alcanza también a otros sujetos que, estando en una posición orgánica de igual a igual o, incluso inferior, aprovechan una situación funcional de superioridad o en esa misma situación anuncian un mal sobre las expectativas legitimas de la víctima en su relación de empleo.

Este será el caso, como ya se puso de relieve en relación con el delito de acoso moral laboral, de los clientes de la empresa o de los representantes de los trabajadores, pues en estos casos, pese a que no exista una relación de superioridad laboral orgánica, puede haberla funcional aprovechando esta situación para cometer el delito. Además, están en posición de utilizar argumentos que condicionen la voluntad de la víctima, creando así una situación similar a la que se produce cuando es el empresario u otros superiores jerárquicos quienes acosan, prevaliéndose de dicha situación.

Pues bien, en el primer caso, tanto en el tipo básico como en el agravado, dependiendo de las concretas circunstancias del caso, no cabe duda de que estos sujetos están en disposición de anunciar

${ }^{74}$ NARVÁEZ BERMEJO, M. A. (1998), ob. cit., p. 95, de donde se han sacado las frases entrecomilladas; y, en similar sentido, BOIX REIG, J. y ORTS BERENGUER, E. (1999), ob. cit., p. 680. En este sentido, la SAP-Murcia, de 21 de septiembre de 1998, n. 82/1998, señala la existencia del delito en relación a una persona a la que no se le ha dado de alta en la Seguridad Social y carece de contrato escrito, pero que ha superado el período de prueba, no regularizándose su situación laboral, pese a que la mujer lo había solicitado, siendo precisamente dicha regularización la que se emplea como condición para conseguir los favores sexuales —sobre esta interpretación SÁNCHEZ, E. y LARRAUI, E. (1999), ob. cit., p. 24

${ }^{75}$ NARVÁEZ BERMEJO, M. A. (1998), ob. cit., p. 94.

${ }^{76}$ BOIX REIG, J. y ORTS BERENGUER, E. (1999), ob. cit., pp. 680 y 681.

${ }^{77}$ NARVÁEZ BERMEJO, M. A. (1998), ob. cit., p. 94

${ }^{78}$ SÁNCHEZ, E. y LARRAUI, E. (1999), ob. cit., p. 24. 
un mal sobre las legítimas expectativas laborales de la víctima introduciendo, por tanto, un límite a su libertad a la hora de reaccionar frente a la solicitud sexual.

Lo mismo cabe decir en relación con los representantes de los trabajadores, pues no hay que olvidar que, en ocasiones, tienen el poder de decidir sobre las condiciones de empleo o el propio empleo de los trabajadores de la empresa. Así, se colocan en una situación de privilegio de la cual pueden prevalerse para solicitar favores sexuales.

En cualquier caso, el tipo no alcanza a las relaciones de igualdad en las que el autor no puede ejercer un poder laboral sobre la víctima, salvo, claro está, que simule dicha situación haciéndola creíble para la víctima ${ }^{79}$.

Por otro lado, el sujeto pasivo del delito será cualquier trabajador de la empresa que se encuentre en una situación de inferioridad laboral en relación con el sujeto activo y que, por tanto, pueda temer sus represalias, ya que está en condiciones de ejercer un perjuicio en el normal desarrollo de su relación laboral.

\subsection{El tipo hiperagravado}

Por último, el apartado tercero del artículo 184 del Código Penal establece una pena aún mayor en situaciones en las que la víctima es especialmente vulnerable "por razón de su edad, enfermedado situación". Así, en estos casos, "la pena será de prisión de cinco a siete meses o multa de 10 a 14 meses en los supuestos previstos en el apartado $1, y$ de prisión de seis meses a un año en los supuestos previstos en el apartado 2 de este artículo".

Se trata por tanto de un agravamiento de la pena que toma en cuenta un criterio subjetivo, como es la situación de especial vulnerabilidad de la víctima. Cuanto mayor es la distancia entre el agresor y quien sufre el acoso, cuanto menor es la capacidad de defensa de este, más reprobable es la conducta. En mi opinión, en estas situaciones, como defendí, la indemnización por los dańos morales causados debería ser especialmente alta ${ }^{80}$.

\section{Notas comunes y divergencias en materia de pena}

En el este último apartado se va a dar cuenta de algunas cuestiones relativas a la pena de estos dos delitos.

\section{a) Penas accesorias}

En primer lugar, ambos tipos de acoso se posibilitan establecer, cuando la gravedad de los hechos o el peligro que represente el delincuente lo aconseje, una serie de medidas de protección para la víctima. Así lo determina el art. 57.1 CP que, en relación con estos y otros delitos, permite a los jueces imponer en la sentencia "la imposición de una o varias de las prohibiciones contempladas en el artículo 48, por un tiempo que no excederá de diez años si el delito fuera grave o de cinco si fuera menos grave". Dichas prohibiciones, de acuerdo con el mencionado art. $48 \mathrm{CP}$, restringen los derechos de comunicación, movilidad y residencia para impedir encuentros y contactos con la víctima, pudiéndose acordar el control de estas medidas por medios electrónicos. Estas penas accesorias serán difícilmente aplicables en

\footnotetext{
${ }^{79}$ NARVÁEZ BERMEJO, M. A. (1998), ob. cit., p. 92

${ }^{80}$ ALTÉS TÁRREGA, J. A. (2008), ob. cit., pp. 117 y ss.
} 
empresas pequeñas en las que habitualmente el trabajador habrá tomado la decisión de dejar el puesto de trabajo y evitar así estos contactos, sufriendo el por tanto el fin que persiguen esta pena accesoria ${ }^{81}$. Así, coincido con la opinión de aquella doctrina que, en relación con el delito de acoso moral, pero igualmente válida para el acoso sexual, que defiende que debería haberse contemplado, "junto con la pena de prisión, alguna pena privativa de derechos como la inhabilitación especial para empleo o cargo público, profesión, oficio o industria. Ello supondría un tratamiento punitivo más coherente con la fenomenología del acoso laboral, pues, además de desplegar ciertos efectos disuasorios, permitiría el alejamiento del acosador respecto de la víctima”, lo que ayudaría a evitar que, como ocurre muchas veces en la práctica, sea la víctima la que acabe trasladándose a otro puesto de trabajo o abandonándolo para no coincidir con su acosador ${ }^{82}$.

\section{b) Necesidad de reformar y armonizar las penas de los delitos}

Los delitos de acoso laboral y acoso sexual muestran algunas disonancias claras que deberían ser corregidas. Me refiero a dos cuestiones de forma específica. La primera tiene que ver con la diferencia de pena entre uno y otro delito. Efectivamente, el delito de acoso laboral tiene una condena de prisión de seis meses a dos ańos, mientras que el acoso sexual en su versión más grave se pena con prisión de seis meses a un año, toda una incongruencia.

Dentro de la categoría general de acoso en las relaciones laborales, el conocido como mobbing o acoso moral y los equiparables acosos discriminatorios, siendo igualmente reprobables, no son tan intrusivos como el acoso sexual, que, además de los bienes protegidos en todo acoso, conculca la libertad sexual de la persona y esta diferencia de gravedad se intensifica todavía más si se trata de un acoso de intercambio en el que las víctimas están en situación de vulnerabilidad. Pese a ello, el Código Penal establece condenas mayores para los primeros que para todos los tipos de acoso sexual, lo que, como acertadamente ha señalado la doctrina penal, "implica, en pocas palabras, que en sentido penológico al acosador le resulta más rentable acosar sexualmente a la víctima, que hacerlo laboralmente mediante actos humillantes de naturaleza no-sexual" ${ }^{83}$.

Por tanto, el legislador debería actuar y de lege ferenda debería, como mínimo, equiparar la pena de ambos delitos, incrementando la de los distintos tipos de acoso sexual del art. $184 \mathrm{CP}^{84}$.

La segunda cuestión, también advertida por la doctrina ${ }^{85}$, tiene que ver con la comparación de la sanción penal del acoso sexual laboral con su homóloga en sede administrativa. Efectivamente si el juez entendiese aplicable la pena de multa en lugar de la prisión, de acuerdo con los parámetros establecidos daría lugar a una sanción económica menor a la establecida en Real Decreto Legislativo 5/2000, de 4 de agosto, por el que se aprueba el texto refundido de la Ley sobre Infracciones y Sanciones en el Orden Social. Efectivamente, el art. 8.13 de esta norma considera como infracción muy grave el acoso sexual, lo que implica una multa que, de acuerdo con el art. 40.1.c de la mima disposición normativa, que se mueve entre 6.251 y 25.000 euros, en su grado mínimo: 25.001 y 100.005 euros, en su grado medio; y 100.006 euros a 187.515 euros en su grado máximo. Sin embargo, si atendemos al acoso sexual penal más grave, la sanción sería como máximo de 400 euros,

\footnotetext{
${ }^{81}$ SANTANA VEGA, D. M. (2013), ob. cit., 879.

${ }^{82}$ BUSTOS RUBIO, M. (2013), ob. cit., p. 46 y 47.

${ }^{83}$ BUSTOS RUBIO, M. (2013), ob. cit., p. 46.

${ }^{84}$ En este mismo sentido, OTERO GONZÁLEZ, P.; POMARES CINTAS, E. (2010), ob. cit., pp. 202-203; y BUSTOS RUBIO, M. (2013), ob. cit., p. 46. Sobre el carácter privilegiado del acoso sexual respecto de unas conductas que comparten rasgos esenciales, en tanto que son un modo de hostigamiento que provoca un clima objetivo y gravemente intimidatorio, hostil y humillante se manifestó también el CGPJ en su Informe al Anteproyecto de reforma del Código Penal de 2009.

${ }^{85}$ DOLZ LAGO, M. (2018), ob. cit., p.
} 
que es la cuota diaria máxima prescrita en el art. $50 \mathrm{CP}$ para la pena de multa a las personas físicas, día durante 14 meses, esto es 168.000 euros.

De nuevo se requiere una intervención legislativa que solvente este desajuste, pues siendo la sanción preferente y excluyente de la sanción administrativa, y en atención al ya mencionado principio de intervención mínima del derecho penal, que solo actúa en relación con los actos punibles más graves, no tiene lógica que el empresario acosador salga beneficiado si se actúa contra él en vía penal.

\section{c) Bibliografía}

ALTÉS TÁRREGA, J. A. (2002), El acoso sexual en el trabajo, Valencia: Tirant lo Blanch.

ALTÉS TÁRREGA, J. A. (2008), El acoso del trabajador en la empresa, Valencia: Tirant lo Blanch.

BARRANCO GÁMEZ, J. M., (2016), Acoso sexual, Diario la Ley, (8749).

BOIX REIG, J. y ORTS BERENGUER, E. (1999), Consideraciones sobre la reforma de los delitos contra la libertad sexual, por la Ley Orgánica 11/1999, Actualidad Penal, (35).

BUSTOS RUBIO, M. (2013), El delito de acoso laboral: exigencias europeas y análisis del tipo penal, Revista de Derecho Penal y Criminología, (1).

CARMONA SALGADO, C. (1996), Comentario al art. 18, en COBO DEL ROSAL M. (Dir.), Curso de Derecho Penal Español. Parte Especial I, Madrid: Marcial Pons

CARMONA SALGADO, C. (2011), Tratamiento jurídico-penal de los acosos laboral, sexual, inmobiliario y escolar a raíz de la reforma de la LO 5/2010 (1), Diario la Ley, (7626)

DOLZ LAGO, M. J. (2018), El acoso ante el derecho: fronteras interdisciplinares, Diario La Ley, (9112).

FERNÁNDEZ PALMA, R. (2010), Acoso laboral e inmobiliario, art. 172.1, párrafos segundo y tercero CP, en QUINTERO OLIVARES, G. (dir.), La reforma penal de 2010: análisis y comentarios, Navarra.

LAMARCA, C. (1996), La protección de la libertad sexual en el nuevo Código Penal, Jueces para la Democracia, (27).

LARRAURI, E. (1997), El nuevo delito de acoso sexual: una primera valoración, Cuadernos de Derecho Judicial, (7).

LOUSADA AROCHENA, J. F. (2003), El acoso moral por razón de género, Aranzadi Social, (15).

LUELMO MILLAN, M. A. (2006), La normativa que viene sobre el acoso moral y sexual y las aportaciones doctrinales y jurisprudenciales más recientes a su tratamiento jurídico, Aranzadi social (12).

MATALLÍN EVANGELIO, A. (2000), El nuevo delito de acoso sexual, Valencia: Ediciones Revista General de Derecho.

MOLINA NAVARRETE, C. (2019-a), ¿La cuestión de género muta hoy en «delito» la «broma» de ayer?: la (infra) valoración judicial de la violencia laboral contra las mujeres, Revista de Trabajo y Seguridad Social. CEF, (433).

MOLINA NAVARRETE, C. (2019-b), Redes sociales digitales y gestión de riesgos profesionales: prevenir el ciberacoso sexual en el trabajo, entre la obligación y el desafío, Diario la Ley, (9452).

MOLINA NAVARRETE, C. (2019-c), La “des-psicologización” del concepto constitucional de acoso moral en el trabajo: ni la intención ni el daño son elementos del tipo jurídico, Revista de Derecho Social (86).

MORALES PRATS, F. y GARCÍA ALBERO, R. (1996), Comentarios al art. 184, en QUINTERO, G. (dir.), Comentarios a la parte especial del Derecho Penal, Pamplona: Aranzadi. 
MUÑOZ CONDE, F. (2019), Derecho penal, parte especial, (22 ed.), Valencia: Tirant lo Blanch, Valencia.

MUÑOZ CUESTA, J. (2020), Rechazo social al trato degradante como atentado a la integridad moral, Revista Aranzadi Doctrinal, (2).

NÚNEEZ FERNÁNDEZ, J. (2010), Aspectos esenciales del nuevo delito de acoso laboral y sus antecedentes jurisprudenciales como trato degradante, Diario La Ley, (7534).

OTERO GONZÁLEZ, P.; POMARES CINTAS, E. (2010), El acoso laboral (mobbing), en ÁLVAREZ GARCÍA, F. J.; GONZÁLEZ CUSSAC, J. L. (dirs.), Comentarios a la reforma penal de 2010, Valencia: Tirant lo Blanch.

PÉREZ DEL RÍO, M. T. (2006), La violencia de género en el trabajo: elementos conceptuales y recepción normativa, en DURÁN LÓPEZ, F., CRUZ VILLALÓN, J.; CASAS BAAMONDE, M. E. (Coord.), Las transformaciones del derecho del trabajo en el marco de la Constitución española: estudios en homenaje al profesor Miguel Rodriguez-Piñero y Bravo Ferrer, Madrid: La Ley.

PÉREZ GINÉS, C. A. (2016), Violencia en el ámbito laboral, Diario La Ley, (8730).

POMARES CINTAS, E. (2009), ¿Protección penal específica del derecho a no sufrir acoso en el trabajo?, en ÁLVAREZ GARCÍA, F. J. (Dir.), La adecuación del Derecho penal español al ordenamiento de la Unión Europea, Valencia: Tirant lo Blanch.

PONS CARMENA, M. (2020), Acoso y violencia en el trabajo a la luz del Convenio OIT no 190 , Labos, (1)2.

RODRIGUEZ INIESTA, G. (2006), El acoso laboral y su protección frente al mismo, en SÁNCHEZ TRIGUEROS, C. (Dir.) La presencia femenina en el mundo laboral: metas y realidades, Navarra: Thomson Aranzadi, 2006.

SALVADOR CONCEPCIÓN, R. (2019), Responsabilidad del empleador como garante ante el acoso psicológico laboral, Revista Aranzadi de Derecho y Proceso Penal, (53).

SÁNCHEZ, E.; LARRAUI, E. (1999), El nuevo delito de acoso sexual y su sanción administrativa en el ámbito laboral, Valencia: Tirant lo Blanch.

SÁNCHEZ GARRIDO, J. A. (2011), La consideración penal del mobbing, Diario la Ley, (7612).

SANTANA VEGA, D. M. (2013), El nuevo delito de acoso laboral (versión en línea), en ÁLVAREZ GARCÍA, F. J.; COBOS GÓMEZ DE LINARES, M. A.; GÓMEZ PAVÓN, P. (coord.), Libro Homenaje al profesor Luis Rodríguez Ramos, Valencia: Tirant lo Blanch.

SERRANO ROMENO, J. F., (2011), Regulación legal del mobbing: laboral, administrativa, civil y penal. Especial referencia a la reforma penal operada en esta materia por LO 5/ 2001, Diario La Ley, (7650).

SOTO SUÁREZ, C. (2013), Supuesto de acoso sexual o el cuidado con las palabras el Código Penal frente al diccionario de la lengua, Diario la Ley (8019).

TRABADO ÁLVAREZ, C., (2011), La regulación penal del delito de mobbing en España, Diario La Ley, (7718).

VILLACAMPA ESTIARTE, C. (2012), La incriminación del mobbing en Derecho penal español: los claroscuros del delito de acoso laboral, Revista de Derecho y Proceso Penal, (30).

VILLEGAS GARCÍA, M. A.; ENCINAR DEL POZO, M. A. (2018), El delito de acoso sexual, Diario La Ley, (9272).

YAGÜE BLANCO, S. (2020), Convenio 190 de la OIT sobre violencia y acoso: delimitación de su ámbito de aplicación ante la posible ratificación por España, Revista General de Derecho del Trabajo y de la Seguridad Social, (57). 